\title{
Moderate alcohol consumption and cognitive risk
}

\author{
This article was published in the following Dove Press journal: \\ Neuropsychiatric Disease and Treatment \\ I I August 201 I \\ Number of times this article has been viewed
}

\author{
Edward J Neafsey \\ Michael A Collins \\ Department of Molecular \\ Pharmacology and Therapeutics, \\ Loyola University Chicago, \\ Stritch School of Medicine, \\ Maywood, IL, USA
}

Correspondence: Edward J Neafsey Department of Molecular Pharmacology and Therapeutics, Loyola University Medical Center, Stritch School of Medicine, 2160 South First Avenue, Maywood, IL 60I53, USA

$\mathrm{Tel}+\mathrm{I} 7082163355$

$\mathrm{Fax}+17082163913$

Email eneafse@lumc.edu
Abstract: We reviewed 143 papers that described the relationship between moderate drinking of alcohol and some aspect of cognition. Two types of papers were found: (1) those that provided ratios of risk between drinkers and nondrinkers ( 74 papers in total) and (2) those that, although they did not provide such ratios, allowed cognition in drinkers to be rated as "better," "no different," or "worse" than cognition in nondrinkers (69 papers in total). The history of research on moderate drinking and cognition can be divided into two eras: 1977-1997 and 1998-present. Phase I (1977-1997) was the era of neuropsychological evaluation involving mostly young to middleaged (18-50 years old) subjects. Although initial studies indicated moderate drinking impaired cognition, many later studies failed to confirm this, instead finding no difference in cognition between drinkers and nondrinkers. Phase II (1998-present) was and is the era of mental status exam evaluation involving mostly older ( $\geq 55$ years old) subjects. These studies overwhelmingly found that moderate drinking either reduced or had no effect on the risk of dementia or cognitive impairment. When all the ratios of risk from all the studies in phase II providing such ratios are entered into a comprehensive meta-analysis, the average ratio of risk for cognitive risk (dementia or cognitive impairment/decline) associated with moderate "social" (not alcoholic) drinking of alcohol is 0.77 , with nondrinkers as the reference group. The benefit of moderate drinking applied to all forms of dementia (dementia unspecified, Alzheimer's disease, and vascular dementia) and to cognitive impairment (low test scores), but no significant benefit against cognitive decline (rate of decline in test scores) was found. Both light and moderate drinking provided a similar benefit, but heavy drinking was associated with nonsignificantly higher cognitive risk for dementia and cognitive impairment. Although the meta-analysis also indicated that wine was better than beer or spirits, this was based on a relatively small number of studies because most studies did not distinguish among these different types of alcohol. Furthermore, a number of the studies that did make the distinction reported no difference among the effects of these different types of alcohol. Therefore, at present this question remains unanswered. Analysis also showed that the presence of the apolipoprotein E epsilon 4 allele eliminated the benefit of moderate drinking. However, this was based on a relatively small number of studies and several other studies have found a beneficial effect of the epsilon e4 allele. Further studies are necessary to settle this question. The benefit of moderate alcohol for cognition was seen in both men and women, although the amount and pattern of drinking is very different between the two sexes. Lastly, the finding of unaffected or significantly reduced cognitive risk in light to moderate drinkers was seen in 14/19 countries for which country-specific ratio data were available, with three of the five remaining countries showing nonsignificant reductions as well. Overall, light to moderate drinking does not appear to impair cognition in younger subjects and actually seems to reduce the risk of dementia and cognitive decline in older subjects.

Keywords: Alzheimer's disease, dementia, drinking 


\section{Introduction}

What is the effect of moderate "social" (not alcoholic) drinking of alcohol on cognition? Does it impair cognition? Does it have no effect on cognition? Or does it enhance or preserve cognition? We have reviewed and analyzed results from studies from the late 1970s through June of 2011, comparing cognitive risk (including dementia, cognitive impairment, and cognitive decline) in moderate social drinkers (not alcoholics) with cognitive risk in nondrinkers.

Our interest in this topic arose from our finding that 6 days of moderate alcohol exposure protects rat organotypic hippocampal-entorhinal cortex brain slice cultures from the toxicity of amyloid- $\beta,{ }^{1}$ the protein that has been strongly implicated in the pathogenesis of Alzheimer's disease (AD). ${ }^{2}$ $\mathrm{We}^{3-6}$ and others ${ }^{7,8}$ have hypothesized a mechanism in which alcohol "protects" by its "preconditioning" effect on neurons and glia, which involves upregulation of heat shock proteins and other cellular pro-survival mechanisms such as $\mathrm{N}$-methyl-D-aspartate receptors, protein kinase $\mathrm{C}$ epsilon, and focal adhesion kinase. This line of research naturally led us to inquire whether there was any evidence that drinking alcohol may "protect" from AD and other forms of dementia or cognitive impairment. There was a large scientific literature addressing this question ${ }^{9-17}$ and our attempt to understand this literature led us to write this review.

\section{Methods}

\section{Search strategies}

The collection of studies reviewed here was assembled primarily by manual search using the bibliographies of each paper and was supplemented by literature searches using the PubMed database. Search terms used for database searches included alcohol or ethanol, dementia, AD, cognition, mild cognitive impairment (MCI), cognitive decline, and memory, all in various combinations. In addition, these terms were also combined with the names of more than 250 countries around the world. This strategy yielded studies providing ratios of risk from 19 countries (Australia, Brazil, Canada, China and Taiwan, Denmark, Finland, France, Germany, Greece, Hungary, Italy, Japan, Korea, the Netherlands, Nigeria, Spain, Sweden, the UK, and the US). Two additional countries (Ireland and Norway) were added to this list from "non-ratio" studies. (The total number increased by eleven if countries included in the Syst-Eur study ${ }^{18}$ were added [Belgium, Bulgaria, the Czech Republic, Estonia, Israel, Lithuania, Poland, Portugal, Romania, the Russian Federation, and
Slovakia], but in this study it was not possible to associate any particular country with its results.)

Unfortunately, studies in languages other than English were not reviewed. In addition, there is no doubt that the search missed some studies for a variety of reasons, and we apologize for these omissions.

\section{Two types of studies}

Two types of studies are distinguished in this review: (1) those providing ratios of risk, such as odds ratios (ORs), risk ratios (RRs), or hazard ratios (HRs) (collectively termed "XRs"); and (2) those that, instead of providing such ratios, could be interpreted in terms of whether some aspect of cognition was "worse," "no different," or "better" in moderate drinkers than in nondrinkers. Historically, the studies without ratios preceded those with ratios, and so that is the order of presentation.

\section{Studies without ratios of risk}

There were 69 studies without ratios of risk that could have results grouped into categories of (1) worse, (2) no different, and (3) better cognition in drinkers than in nondrinkers, or in heavy drinkers than in light drinkers. The data in these three categories were plotted as cumulative sum histograms of the numbers of studies accumulating each year from 1975 to 2011. (A cumulative sum is a sequence of partial sums of a given sequence; for example, the cumulative sums of the sequence $1,2,1$ are $1,3,4$.) These histogram plots provide valuable information on the history of the field, including when studies in each category occurred and for how long and at what rate they continued to accumulate in each category. Data concerning the type of cognitive testing employed and the age of the subjects in the studies are also plotted.

\section{Studies with ratios of risk}

There were 74 studies that provided various ratios of risk, including ORs, RRs, or HRs. Such numbers allowed for relatively direct comparisons among studies and were used for meta-analysis. The XRs were pooled and plotted together in forest plots because such ratios are roughly equivalent when describing events such as $\mathrm{AD}$ or $\mathrm{MCI}$ that are relatively rare or uncommon. ${ }^{19-22}$

The present review does not follow what has become the conventional method for meta-analysis in which only a subset of studies that meet certain criteria for quality are selected for analysis from a larger set of studies collected in a field. ${ }^{23-25}$ Instead, and perhaps closer to the original concept 
of meta-analysis, which called for liberal inclusion criteria that incorporate "all studies, good bad and indifferent" 26 and for considering the unit of analysis to be all the findings from each study and not just one summary value for each study, ${ }^{26}$ we chose to "uncritically" collect data from as many studies as possible and thus present the "big picture," both for its own value and as a complement and a context for more restricted or selective meta-analyses. Therefore, if a study reported $1 \mathrm{OR}$ or 50, all were included in the analysis. The second reason is that several meta-analyses of the effects of moderate drinking on cognition that employed the conventional, more restricted sample method have recently been published. ${ }^{11,12}$

The normal meta-analysis method of presenting a forest plot and calculating an overall ratio with its $95 \%$ confidence intervals (CIs) was followed. Since such an "uncritical" metaanalysis includes the effects of moderate drinking on a broad spectrum of cognitive function - including dementia, cognitive impairment, and cognitive decline - and different methods of measuring cognition, the presence of significant "heterogeneity" or inconsistency among studies ${ }^{27-29}$ was determined. This was achieved by calculating the $P$-value (Qp) of the $Q$ statistic (the weighted sum of squared differences between individual study effects and the pooled effect across studies) and the percentage of variability due to heterogeneity rather than chance $\left(\mathrm{I}^{2}\right)$; these two numbers are reported in the forest plot figures and commented on in the text. The results of a random-effects model are always reported in the forest plots on the left-hand side of the figures. On the right-hand side of the figures are found plots of the "approximately normal" 30 distributions of the logs of the ratios ( $\log [\mathrm{XR}]$ values), along with the results of a fixed-effects model. In addition, small inset quantile-quantile (Q-Q) plots of the $\log (\mathrm{XR})$ values are presented to better display any deviations from normality; small inset funnel plots are also presented, to aid detection of "publication bias." 31,32 The tops of the funnel plots are labeled with the $P$-values of two tests for funnel plot asymmetry, the regression test ${ }^{31}$ on the left and the rank correlation test $^{33}$ on the right.

The open-source R statistical program ${ }^{34}$ and its metafor package, which can be obtained from http://www.r-project.org and http://www.metafor-project.org, respectively, were used to carry out the statistical meta-analysis and generate the plots.

\section{Results}

\section{Does moderate drinking affect cognitive risk?}

Before answering this question, because the methods of measuring cognition and the ages of the subjects studied have changed in important ways since 1977, it is important to describe the history of research in this field. This history begins with studies without ratios of risk, since the early work did not provide such ratios.

\section{Cognition in studies without ratios of risk}

Figure 1 and Table 1 summarize the results from these 69 studies, which included a total of 111,909 subjects (56,934 women and 54,906 men) and provided a total of 87 judgments of whether cognition was worse, no different, or better in drinkers than in nondrinkers or in heavy drinkers than in light drinkers (there are more judgments than studies because some studies reported results for men and women separately). Of these 69 studies, 46 were from the US, 13 from Europe (Denmark; Finland; France; the Netherlands; Ireland, Scotland, Norway; Sweden; and the UK), seven from Australia, two from Asia (China and Japan), and one from Canada. As seen in Figure 1, the 1977 study by Parker and Noble $^{35}$ is considered the beginning of investigation of alcohol's effect on cognition in social drinkers. It reported worse cognition in social drinkers that was related to the quantity of alcohol consumed per occasion; this study is labeled along the $\mathrm{x}$-axis as the first element on the "Worse" histogram (heavy, solid gray line). These authors concluded that their results supported the "continuity hypothesis" of Ryback ${ }^{36}$ that proposed, as summarized by Parsons and Nixon, that "there is a continuum of alcohol effects on the brain, ranging from the profound memory and abstracting impairment found in patients with Korsakoff's disease, through the moderate cognitive impairments found in non-Korsakoff alcoholics, to mild cognitive impairments that might be present in heavy to moderate social drinkers." ${ }^{37}$ However, within a few years studies reporting no difference ("NoDiff" histogram; left, heavy black line) in cognition between drinkers and nondrinkers began to appear, and such studies have continued to accumulate up to the present (43 studies in total), while the "Worse" histogram plateaued and eventually stopped accumulating in 2003 (only 14 studies in total). In 1998 a third histogram (right, heavy black line) of studies reporting "Better" cognition in moderate drinkers began accumulating more rapidly (one study reporting "better" was seen earlier, in 1987), and this has continued up to the present (30 studies in total).

Why did these studies finding "better" cognition in drinkers start appearing so late? There appear to be two reasons for the late appearance of better cognition in drinkers. First, more than $60 \%(18 / 29)$ of these "better" studies used some 
type of mental status exam (thin dotted line labeled b+mse in Figure 1), such as the Mini-Mental State Examination (MMSE), the Telephone Interview for Cognitive Status ${ }^{\mathrm{TM}}$ (TICS ${ }^{\mathrm{TM}}$ ), the TELE telephone interview, the Modified Mini-Mental State (3MS) examination, or the Cognitive Abilities Screening Instrument. Only one study employed a mental status exam before 1998; therefore, the history of studies of alcohol and cognition in social drinkers (not alcoholics) can be divided into two phases, with phase II (1998-2011) being the "mental status" era, as labeled in Figure 1. Phase II is also characterized by more studies of older subjects ( $\geq 55$ years old, thin dashed line labeled gte55 in Figure 1) than in phase I.

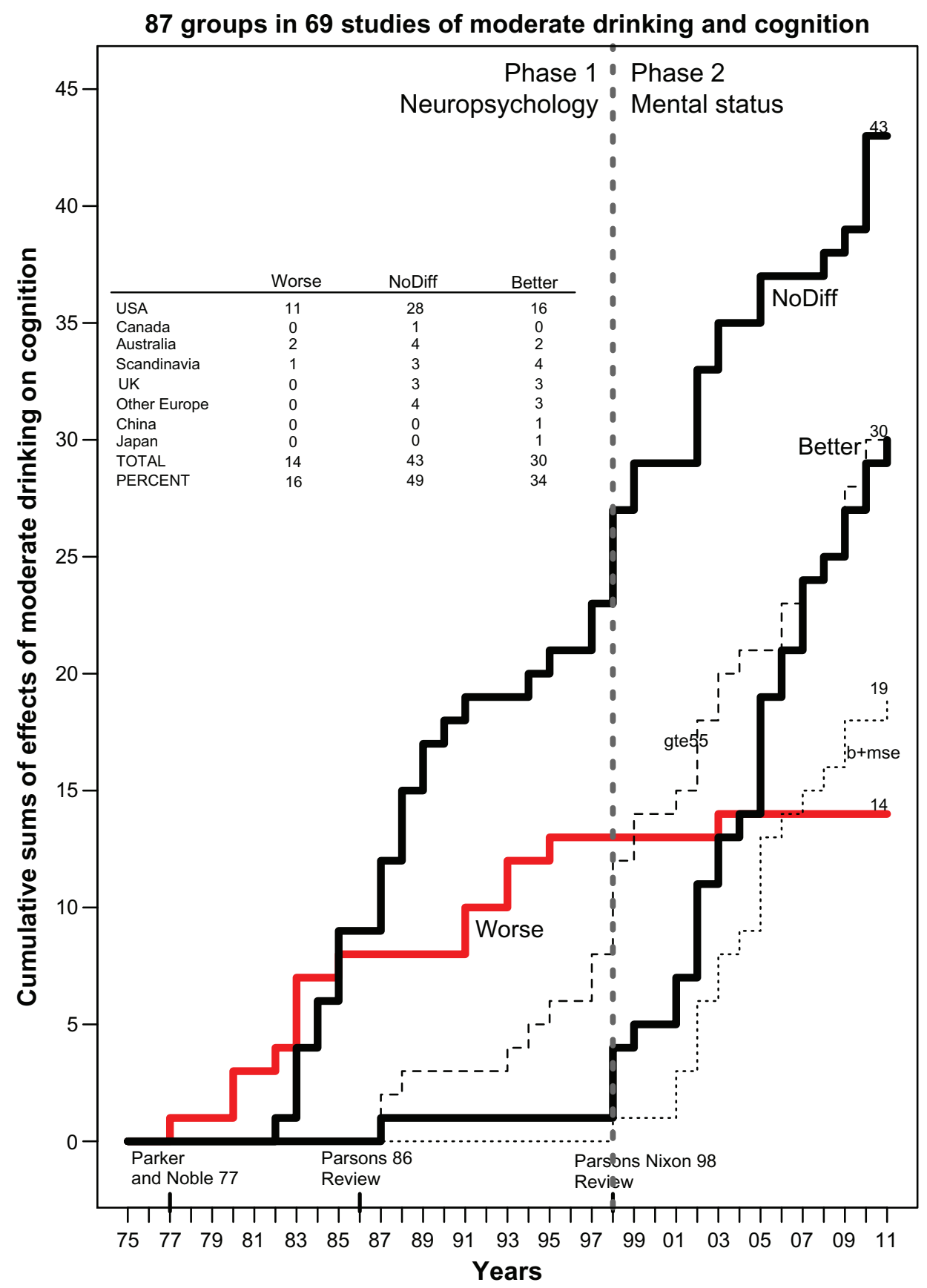

Figure I Cumulative sum histograms (heavy lines) of numbers of studies that did not report various ratios or risk but instead reported "Worse" (heavy solid gray line), "NoDiff" (left, heavy solid black line), or "Better" (right, heavy solid black line) cognition in "social" drinkers (not alcoholics) versus nondrinkers from I975 to 201 I. Thin dotted line at the lower right plots the cumulative sum histogram for studies that reported better cognition and used a MSE to evaluate cognition (b+mse). Thin dashed line plots the cumulative sum histogram for studies of subjects who were $\geq 55$ years of age (gte55). Dashed vertical line at 1998 separates two phases of research on this question (phase I: neuropsychology; phase II: mental status). Inset table shows the breakdown by country of studies reporting worse, no different, or better cognition in drinkers. Abbreviations: $\mathrm{Cl}$, confidence interval; b, better; ge55, $\geq 55$ years of age; HR, hazard ratio; MSE, mental status exam; NoDiff, no different; OR, odds ratio; RR, risk ratio; UK, United Kingdom; USA, United States of America. 
Table I Cognitive performance in drinkers in "non-ratio" studies, 1977-1986, 1986-1996, and 1997-present

\section{$1977-1986(n=17)$ \\ Worse $(8 / 17=47 \%)$}

Parker and Noble ${ }^{35}$ : $102 \mathrm{~m}$

Parker et $\mathrm{al}^{40}: 481 \mathrm{~m}$

Parker et al ${ }^{44}: 45 \mathrm{~m}$

Jones and Jones ${ }^{46}: 32 \mathrm{f}$

MacVane et $\mathrm{al}^{48}: 106 \mathrm{~m}$

Hannon et a ${ }^{50}: 40 \mathrm{~m}$

Hannon et $a^{50}: 52 \mathrm{f}$

Bergman $^{51}$ : $195 \mathrm{~m}$

1 $986-1996(\mathrm{n}=18)$

Worse $(4 / 18=22 \%)$

Parker et al ${ }^{39}: 481 \mathrm{~m}, 544 \mathrm{f}$

Martin et al $\left.\right|^{55}$ : I $19 \mathrm{~m}, 134 \mathrm{f}$

Mangione et $\mathrm{al}^{60}: 190 \mathrm{~m}, 282 \mathrm{f}$

Fox et al ${ }^{62}: 26 \mathrm{~m}, 5 \mathrm{f}$

1997-present ( $n=52)$

Worse $(1 / 52=2 \%)$

Schinka et al ${ }^{41}: 230 \mathrm{mf}$
No difference $(9 / 17=53 \%)$

Parker et $\mathrm{a}^{40}: 544 \mathrm{f}$

Parker et al ${ }^{43}: 21 \mathrm{~m}, 60 \mathrm{f}$

Birnbaum et al ${ }^{45}: 93 \mathrm{f}$

Cala et a ${ }^{47}: 24 \mathrm{~m}, 15 \mathrm{f}$

Hannon et al ${ }^{49}: 67 \mathrm{~m}, 103 \mathrm{f}$

Bergman $^{51}: 192 \mathrm{f}$

Hunt et $\mathrm{a}^{52}: 41 \mathrm{~m}, 39 \mathrm{f}$

Parsons ${ }^{53}: 100 \mathrm{~m}$

Jones-Saumty and Zeiner ${ }^{54}: 80 \mathrm{mf}$

\section{No difference $(12 / 18=67 \%)$}

Carey and Maisto ${ }^{56}: 85 \mathrm{f}$

Page and Cleveland $d^{58}: 322 \mathrm{~m}$

Bowden ${ }^{61}: 23 \mathrm{~m}, 17 \mathrm{f}$

Goodwin et al63: $124 \mathrm{~m}, 146 \mathrm{f}$

Emmerson et $\mathrm{a}^{64}: 80 \mathrm{~m}$

Alterman and Hall65: $95 \mathrm{~m}$

Waugh et $\mathrm{al}^{66}: 131 \mathrm{~m}$

Bates and Tracy ${ }^{67}: 654 \mathrm{~m}, 654 \mathrm{f}$

Salamé ${ }^{68}: 72 \mathrm{~m}$

Scherr et al ${ }^{69}: 1382 \mathrm{~m}, 2241 \mathrm{f}$

Arbuckle et $\mathrm{al}^{70}: 140 \mathrm{~m}$

Christian et $\mathrm{al}^{71}: 4739 \mathrm{~m}$

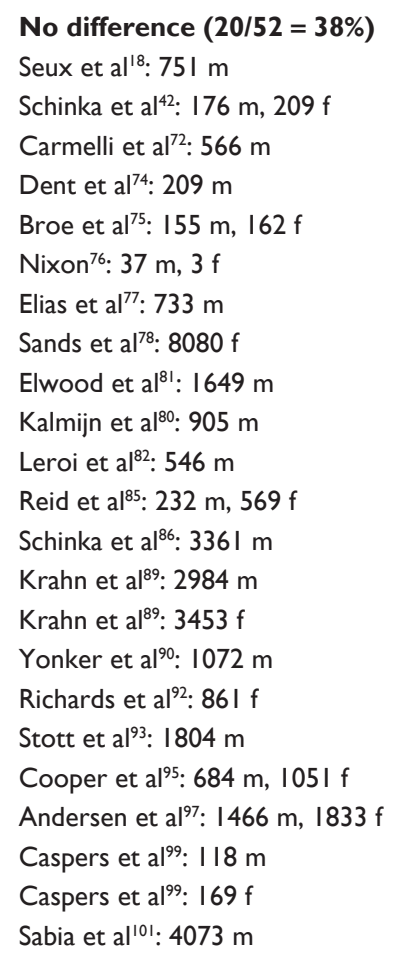

Better $(0 / 16=0 \%)$

Better (2/18 = I I\%)

Farmer et al ${ }^{57}: 834 \mathrm{~m}, \mathrm{I} / 98 \mathrm{f}$

Nichols et al ${ }^{59}: 22 \mathrm{~m}$

\author{
Better (28/52 = 54\%) \\ Seux et al ${ }^{18}: 1474 \mathrm{f}$ \\ Cerhan et $\mathrm{al}^{73}: 6156 \mathrm{~m}$ \\ Cerhan et $\mathrm{al}^{73}:$ 771 I f \\ Elias et $\mathrm{al}^{77}: 1053 \mathrm{f}$ \\ Bond et al ${ }^{79}: 808 \mathrm{~m}$ \\ Bond et al ${ }^{79}: 1028 \mathrm{f}$ \\ Kalmijn et $\mathrm{al}^{80}: 989 \mathrm{f}$ \\ Leroi et $\mathrm{al}^{82}$ : $942 \mathrm{f}$ \\ Wang et al ${ }^{83}: 1058 \mathrm{~m}, 1520 \mathrm{f}$ \\ Bond et a $\left.\right|^{84}: 1856 \mathrm{~m}$ \\ Bond et al ${ }^{84}: 255 \mathrm{I} \mathrm{f}$ \\ Zimmerman et al ${ }^{87}$ : $182 \mathrm{f}$ \\ Lindeman et a ${ }^{88}: 438 \mathrm{~m}, 389 \mathrm{f}$ \\ Yonker et al ${ }^{90}: 1152 \mathrm{f}$ \\ Rodgers et al ${ }^{91}: 3122 \mathrm{~m}$ \\ Rodgers et $\mathrm{al}^{91}: 328 \mathrm{f}$ \\ Richards et al92: $903 \mathrm{~m}$ \\ Reid et al ${ }^{94}: 760 \mathrm{~m}$ \\ McDougall et $\mathrm{al}^{96}: 60 \mathrm{~m}$ \\ Ngandu et al ${ }^{98}: 506$ m, $835 \mathrm{f}$ \\ Lang et al ${ }^{100}: 3409 \mathrm{~m}$ \\ Lang et al ${ }^{100:} 3877 \mathrm{f}$ \\ Stott et al ${ }^{93}: 3000 \mathrm{f}$ \\ Townsend et al ${ }^{102}: 1698 \mathrm{f}$ \\ $X u$ et al ${ }^{103}: 176 \mathrm{~m}$ \\ Arntzen et al ${ }^{104:} 2227 \mathrm{~m}$ \\ Arntzen et al ${ }^{104:} 2806 \mathrm{f}$ \\ Yamazaki et al ${ }^{105}$ : $130 \mathrm{~m}, \mathrm{I} 10 \mathrm{f}$
}

Notes: First section covers 17 studies without ratios from 1977 to 1986, reviewed by Parsons. ${ }^{38}$ second section covers 18 studies without ratios from 1986 to 1996 , reviewed by Parsons and Nixon. ${ }^{37}$ Third section covers 52 studies without ratios from 1997 to the present. Some studies provide separate results for men $(\mathrm{m})$ and women $(\mathrm{f})$. 
During phase I (1977-1997), in contrast, the studies measured various aspects of cognition primarily by a wide variety of neuropsychological tests, such as the Shipley Institute of Living Scale, the Wechsler Adult Intelligence Scale, the Wisconsin Card Sorting Test, various components of the Halstead-Reitan Neuropsychological Test Battery such as the Trail Making Test or the Category Test, the Stroop ColorWord Test, and others. For this reason, phase I is labeled as "Neuropsychology" in Figure 1. The results of phase I studies of the relationship between social drinking and cognition were summarized in two reviews authored by Parsons, one in $1986^{38}$ and the other, authored with Nixon, in 1998. ${ }^{37}$ The earlier review concluded that "there are no stable or reproducible specific relationships" between drinking and performance on certain cognitive-perceptual tests and that "the results of studies to date are inconclusive. ${ }^{138}$ The later review concluded that "heavy social drinkers had significantly worse performance on one or more cognitive tests than the light drinkers," supporting the alcohol-causal-threshold hypothesis that "persons drinking five or six US standard drinks per day over extended time periods manifest some cognitive inefficiencies." Therefore, light to moderate drinking was not consistently associated with any cognitive deficits, although the evidence continued to be "fragmentary and in need of replication." ${ }^{37}$ This conclusion is further supported by the reanalysis by Parker et $\mathrm{al}^{39}$ of their earlier study. ${ }^{40}$ The reanalysis found that the cognitive deficits they had reported earlier were due to the effects of heavy drinkers (almost daily consumption of four drinks), since in lighter drinkers (two drinks/occasion, 1.6 times/week) "neither the quantity of alcohol consumed per occasion nor the frequency of consumption significantly predicted abstraction performance." ${ }^{39}$

Table 1 lists the various studies that were included in Figure 1. The first and second sections of the table list studies during phase I, as discussed. The third section of Table 1 covers the period from 1997 to the present. Note that only 1/52 (2\%) studies during this period found that social drinkers were cognitively worse than nondrinkers. In that study, of 230 male and female elderly African-Americans, Schinka et a ${ }^{41}$ reported that "medium intensity" (30-60 drinks/month) moderate drinkers $(n=25)$ had poorer general cognitive performance (3MS, Hopkins Verbal Learning Test, and Stroop test) than both nondrinkers $(\mathrm{n}=116)$ and "high intensity" $(>119$ drinks/ month) heavy drinkers $(\mathrm{n}=18)$. However, the same study's hierarchical multiple regression analysis found drinking significantly "explained" variance in general cognition (2.4\%), memory (4.8\%), and executive function $(4.9 \%)$, and the overall influence was beneficial or "facilitatory" - ie, drinking improved scores. Therefore, although listed in Table 1 in the "Worse" column, this study could also have been listed under "Better." Furthermore, Schinka et $\mathrm{al}^{41}$ point out their study is inconsistent with their own work using identical methods to study an elderly, mostly white sample ${ }^{42}$ in which no significant effects of drinking or drinking intensity on cognition were seen. Shifting to the other categories, in 20/52 (38\%) of the studies no difference was seen between drinkers and nondrinkers, and, in contrast to earlier research, better cognitive performance was seen in 28/52 (54\%) of the studies. Many of these studies reporting better cognition in drinkers used mental status exams to evaluate cognition and also studied older ( $\geq 55$ years old) subjects.

In summary, when "no ratio" studies are reviewed, it appears that, when evaluated by standard psychological tests in younger subjects ( $<55$ years old), heavy drinking (4-6 drinks/day) is associated with cognitive impairment (the alcohol-causal-threshold hypothesis). However, there is no significant difference in cognition between light to moderate drinkers and nondrinkers. Interestingly, when various mental status exams are used to assess cognition, it appears that drinkers have a reduced risk of dementia or cognitive impairment compared with nondrinkers.

\section{Cognition in studies with ratios of risk}

As seen in the forest plot in Figure 2A and in Table 2, the 74 studies with ratios provided 446 ratios of risk (XRs) and included 253,791 subjects, including 173,970 women and 122,033 men. For 68 studies (92\%), the subjects were aged $\geq 55$ years, while for 52 studies $(70 \%)$ the subjects were aged $\geq 65$ years. About $87 \%$ of the ratios (388/446) were derived from studies that employed mental status exams as all or part of the measure of cognition. Eighty percent of these studies took place since 1998 and therefore can be considered part of the phase II mental status era. Of these 74 studies, 30 were from the US, 25 from Europe (Denmark, Finland, France, Germany, Greece, the Netherlands, Hungary, Italy, Spain, Sweden, and the UK), eight from Asia (China, Japan, Korea, and Taiwan), three from Australia, five from Canada, two from Africa (Nigeria), and one from South America (Brazil).

As seen in Figure 2A, the overall weighted mean value $\left(\mathrm{XR}_{\mathrm{wm}}\right)$ from a random-effects meta-analysis was 0.77 , and the $95 \% \mathrm{CI}$ was relatively narrow $(0.73-0.80)$, showing a significantly reduced risk for dementia, cognitive impairment, or cognitive decline in the drinkers. Significant 
heterogeneity was present $\left(I^{2}=83.1 \% ; \mathrm{Qp}=0.0000\right)$. Since it is the $\log (\mathrm{XR})$ values that have an approximately normal distribution, ${ }^{30}$ Figure 2B shows a histogram and smoothed (solid line) plot of all $\log (\mathrm{XR})$ values. Although both low and high ends of $\log (\mathrm{XR})$ distribution diverge slightly from normal compared with a pure normal distribution created with the same mean and variance (dashed line), the plot illustrates nonetheless that the $\log (\mathrm{XR})$ distribution is close to normal, with a mean of -0.278 . This normality is also seen in the small inset normal Q-Q plot at the lower left of the figure. The funnel plot at the lower right was relatively symmetric and did not indicate publication bias. Taking the antilog of the mean gives an $\mathrm{XR}_{\mathrm{m}}$ of 0.76 (almost identical to that seen for the weighted average random-effects analysis) with a relatively narrow $95 \% \mathrm{CI}(0.71-0.81)$, showing a significant reduction in cognitive risk in drinkers. The basic normality of the $\log (\mathrm{XR})$ distribution is consistent with it being close to the actual population distribution; therefore, it shows a real and beneficial effect of light to moderate drinking that reduces the risk of dementia, $\operatorname{cog}$ nitive impairment, and cognitive decline in older adults by $20 \%-25 \%$.

\section{Does it make any difference if the reference group} of nondrinkers includes former drinkers, who might be considered "sick quitters"?

One criticism of studies reporting lower risk or better outcome in light to moderate drinkers is that the reference group of nondrinkers or nondrinkers includes former drinkers who might be considered "sick quitters"; this may bias the results by making the reference group "sicker" than it really is and, by comparison, make drinkers appear better off than they really are. ${ }^{179-183}$ However, Figure 3 shows that 19 studies with 191 ratios excluded former drinkers from the reference group and still found a protective effect of drinking $\left(\mathrm{XR}_{\mathrm{wm}}=0.79[95 \%\right.$ CI: $0.75-0.84] ; \mathrm{XR}_{\mathrm{m}}=0.72$ [95\% CI: 0.66-0.80]).
A $\quad$ All: $X R_{w m}=0.77(0.73,0.80)$

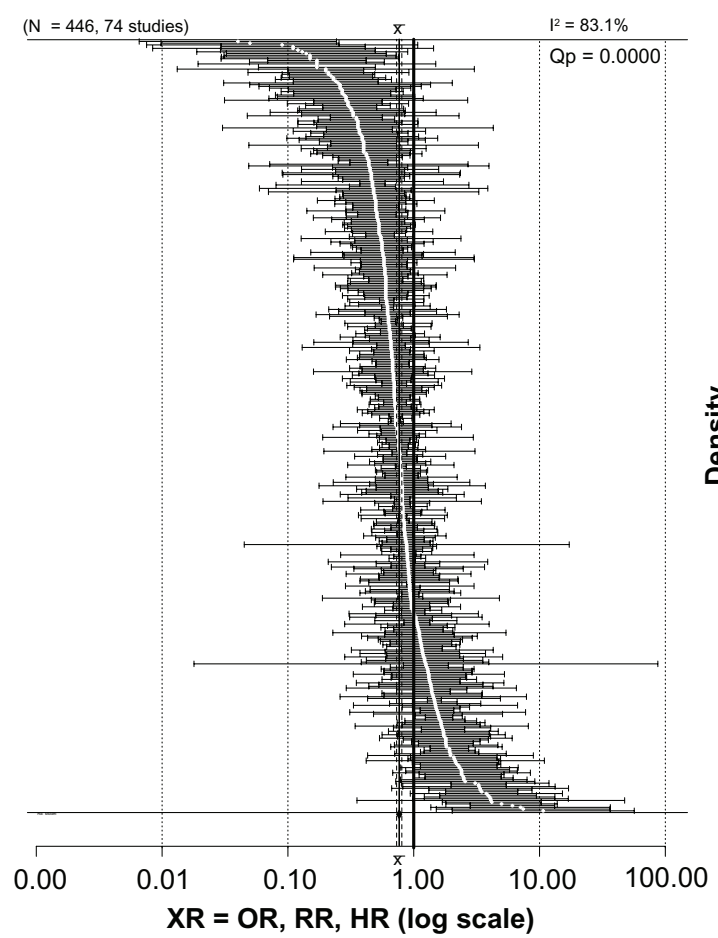

B

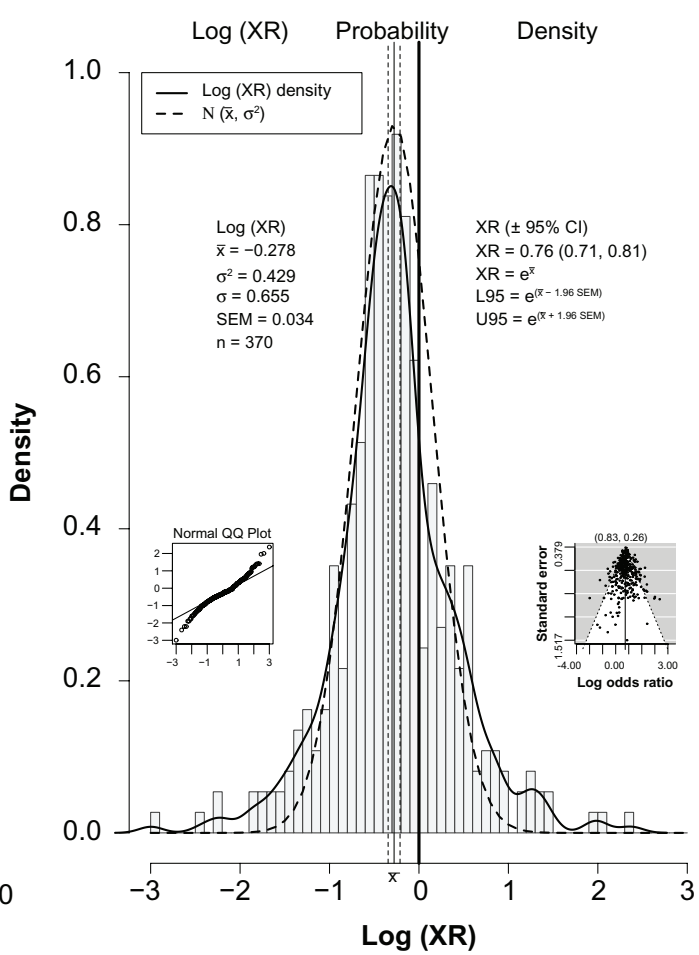

Figure 2 (A) Forest plot of all 446 XRs (white dots) plus or minus their 95\% Cls (horizontal "whiskers") from 74 studies providing ratios; ratios are listed in order from smallest to largest. $\mathrm{XR}_{w \mathrm{~m}}$ is the weighted $\left(\mathrm{wt}=\mathrm{I} / \mathrm{SEM}{ }^{2}\right.$ ) mean of all 446 ratios from a random-effects meta-analysis model with $95 \% \mathrm{Cl}$ in parentheses. Mean value $\pm 95 \%$ $\mathrm{Cl}$ is to the left of and significantly less than the thick solid vertical line at 1.00 that denotes no difference; this value indicated on the plot's $\mathrm{x}$ axis with $\pm 95 \% \mathrm{Cl}$ (vertical dashed lines). (B) Histogram of the probability density of the $\log (X R)$ values with a superimposed smooth probability density curve (solid line) and a superimposed normal distribution density curve (dashed line) calculated using the mean and variance of $\log (X R) . X R_{m}$ is the simple (not weighted) antilog of the mean of all log(XR) values with the $95 \% \mathrm{Cl}$ in parentheses; this value indicated on the plot's $\mathrm{x}$ axis with $\pm 95 \% \mathrm{Cl}$ (vertical dashed lines). Small inset graph on left is a normal Q-Q plot showing normality and departures from normality of the $\log (\mathrm{XR})$ distribution. Small inset graph on right is funnel plot with $P$-values for regression (left) and rank correlation (right) tests for asymmetry across top. Note that $X_{m}$ is identical to $X R_{w m}$

Abbreviations: $\mathrm{Cl}$, confidence interval; HR, hazard ratio; NoQuitters, no quitters; OR, odds ratio; Q-Q, quantile-quantile; RR, risk ratio; SEM, standard error of the mean; wt, weight; $X R s$, hazard ratios, odds ratios, and risk ratios; $X R_{w m}$, weighted mean ratio. 
Table 2 The 74 studies providing ratios of risk listed by decade

\begin{tabular}{|c|c|c|}
\hline $1980 s(n=4)$ & $1990 s(n=14)$ & $2000 s(n=53)$ \\
\hline Heyman et al ${ }^{106}$ & Hofman and van Duijn 107 & Cervilla et al ${ }^{108}$ \\
\hline French et al ${ }^{109}$ & Iliffe et al ${ }^{110}$ & Commenges et $\mathrm{al}^{\prime \prime \prime}$ \\
\hline Amaducci et $\mathrm{al}^{1 / 2}$ & Hebert et al ${ }^{113}$ & Galanis et al ${ }^{114}$ \\
\hline Guralnik and & Ensrud et al ${ }^{116}$ & Hébert et al ${ }^{117}$ \\
\hline \multirow[t]{52}{*}{ Kaplan ${ }^{115}$} & Yoshitake et al ${ }^{118}$ & Tyas et al ${ }^{119}$ \\
\hline & Hendrie et $\mathrm{al}^{120}$ & DeCarli et al ${ }^{121}$ \\
\hline & Launer et al ${ }^{122}$ & Zuccala et al $\left.\right|^{123}$ \\
\hline & Dufouil et al ${ }^{124}$ & Huang et al $\left.\right|^{125}$ \\
\hline & Orgogozo et al $\left.\right|^{126}$ & Lindsay et al ${ }^{127}$ \\
\hline & Tsolaki et al ${ }^{128}$ & Ruitenberg et al ${ }^{129}$ \\
\hline & Edelstein et $\mathrm{al}^{130}$ & Tanaka et $\mathrm{al}^{|3|}$ \\
\hline & Carmelli et al $\left.\right|^{132}$ & Truelsen et al ${ }^{133}$ \\
\hline & Harwood et al ${ }^{134}$ & Bachman et al (USA) $)^{135}$ \\
\hline & Leibovici et al ${ }^{136}$ & Bachman et al (Nigeria) ${ }^{135}$ \\
\hline & & Mukamal et al ${ }^{137}$ \\
\hline & & Zhou et al ${ }^{138}$ \\
\hline & & Anttila et al $\left.\right|^{139}$ \\
\hline & & Britton et al ${ }^{140}$ \\
\hline & & Larrieu et $a^{141}$ \\
\hline & & Luchsinger et al $\left.\right|^{142}$ \\
\hline & & Espeland et $\mathrm{al}^{143}$ \\
\hline & & Ganguli et al ${ }^{144}$ \\
\hline & & Järvenpää et al $\left.\right|^{145}$ \\
\hline & & Rozzini and Trabucci'146 \\
\hline & & Stampfer et al $\left.\right|^{147}$ \\
\hline & & Dai and Pruett ${ }^{148}$ \\
\hline & & Deng et al $^{149}$ \\
\hline & & Ogunniyi et al ${ }^{151}$ \\
\hline & & Simons et al $\left.\right|^{152}$ \\
\hline & & Wright et al ${ }^{153}$ \\
\hline & & Yip et al ${ }^{154}$ \\
\hline & & McGuire et al ${ }^{155}$ \\
\hline & & Solfrizzi et al ${ }^{156}$ \\
\hline & & Vincze et al ${ }^{157}$ \\
\hline & & Wadley et al ${ }^{158}$ \\
\hline & & Kivipellto et al ${ }^{159}$ \\
\hline & & Mehlig et $\mathrm{al}^{160}$ \\
\hline & & Umegaki et al ${ }^{161}$ \\
\hline & & Barnes et al ${ }^{162}$ \\
\hline & & Cherbuin et al ${ }^{163}$ \\
\hline & & Peters et $\mathrm{al}^{164}$ \\
\hline & & Sabia et al ${ }^{165}$ \\
\hline & & Yaffe et al ${ }^{166}$ \\
\hline & & Chan et $\mathrm{al}^{167}$ \\
\hline & & Garcia et al ${ }^{168}$ \\
\hline & & Lobo et al ${ }^{169}$ \\
\hline & & Lopes et al ${ }^{170}$ \\
\hline & & Luck et $\mathrm{al}^{171}$ \\
\hline & & Smith et $\mathrm{al}^{172}$ \\
\hline & & Virtaa et al ${ }^{173}$ \\
\hline & & Yen et $\mathrm{al}^{174}$ \\
\hline & & Au Yeung et al ${ }^{175}$ \\
\hline & & Gureje et $\mathrm{al}^{150}$ \\
\hline & & Kim et al $\left.\right|^{176}$ \\
\hline & & Rusanen et al $\left.\right|^{177}$ \\
\hline & & Weyerer et al ${ }^{178}$ \\
\hline
\end{tabular}

Note: Most (about $80 \%$ ) of the studies took place after 1998 in the mental status era.
For example, Hendrie et a ${ }^{120}$ used lifetime nondrinkers as the reference group, thereby avoiding former drinkers. Zuccala et a ${ }^{123}$ attempted to compensate for the presence of sick quitters in the reference group of nondrinkers by adjusting for a comorbidity covariate. Ruitenberg et a ${ }^{129}$ reported that the HR for dementia in light to moderate drinkers when subjects with changed drinking patterns were excluded was 0.57 (95\% CI: $0.36-0.89$ ), which is virtually the same as the HR of 0.58 (95\% CI: 0.38-0.90) when they were not excluded. Mukamal et $\mathrm{al}^{137}$ did not include either former drinkers or quitters in his reference group of nondrinkers, noting that "former drinkers and quitters had approximately $20 \%$ to $60 \%$ higher odds of dementia than long-term nondrinkers." Anttila et al ${ }^{139}$ found an OR of 0.48 (95\% CI: 0.24-0.95) for cognitive impairment in infrequent drinkers when compared with a reference group of "never" drinkers that did not include former drinkers. The ORs for poor cognitive performance from the study of Britton et $\mathrm{al}^{140}$ used a reference group of those who reported drinking within the past year but not in the past week, thereby avoiding questions associated with comparisons between former drinkers and nondrinkers. Similarly, when Ganguli et $\mathrm{al}^{144}$ compared the minimal drinking group with life-long nondrinkers (excluding quitters), the lower odds of decline on the MMSE of 0.05 (95\% CI: 0.01-0.26) remained significant; this also was seen for the ratio for the moderate drinking group for decline on the MMSE of 0.27 (95\% CI: 0.09-0.84). Stampfer et al ${ }^{147}$ excluded former drinkers or drinkers whose consumption greatly declined from the reference group of nondrinkers. Wright et a $1^{153}$ distinguished past drinkers from "never drinkers" and only included the latter in their reference group; likewise, Yip et al ${ }^{154}$ used never drinkers as the reference category. The HRs from Solfrizzi et a ${ }^{156}$ showing a lower hazard of progression from MCI to dementia in light drinkers of alcohol of 0.15 (95\% CI: 0.03-0.78) and light drinkers of wine of 0.15 (95\% CI: 0.03-0.77) used a nondrinkers reference group from which former drinkers were excluded. Wadley et $\mathrm{a}^{158}$ used life-long nondrinkers as the reference group. The reduced HR for dementia of 0.56 (95\% CI: $0.38-0.82)$ in female wine drinkers seen in the study by Mehlig et a ${ }^{160}$ was maintained when former drinkers were included as drinkers rather than as nondrinkers. Lobo et al ${ }^{169}$ excluded former drinkers from the reference group of nondrinkers.

\section{Is there any common factor in the ratios that} showed significantly worse cognition in drinkers?

Of the 446 ratios in Figure 2, 123 (28\%) were significantly less than 1, indicating less risk or "better" cognition in drinkers; 300 (67\%) were not significantly different than 1 , 
A No quitters: $\mathrm{XR}_{\mathrm{wm}}=0.79(0.75,0.84)$

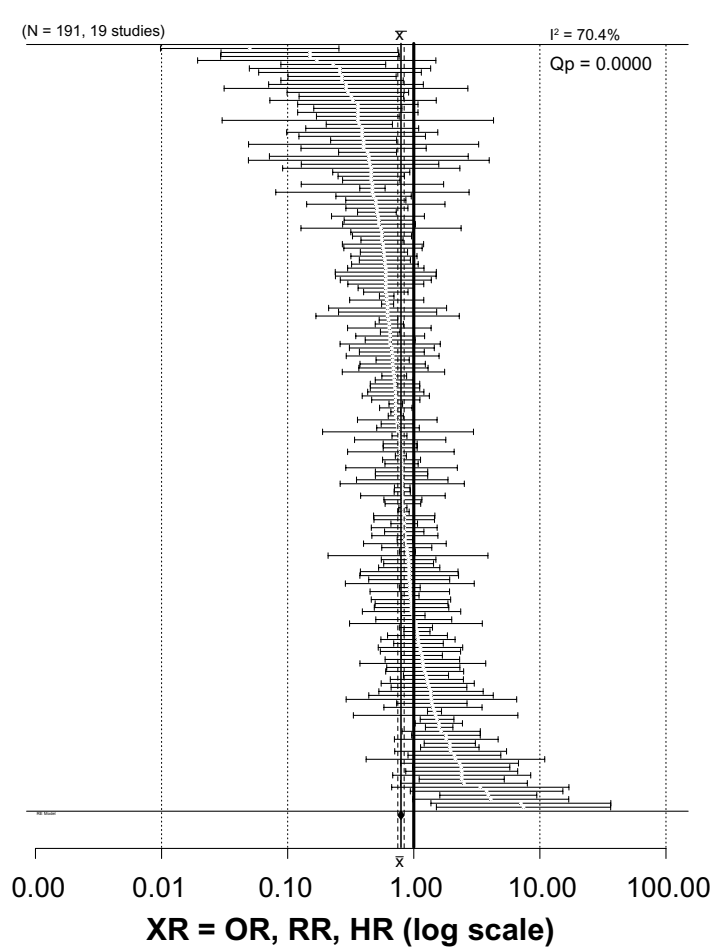

B No quitters: $\mathrm{XR}_{\mathrm{m}}=0.72(0.66,0.80)$

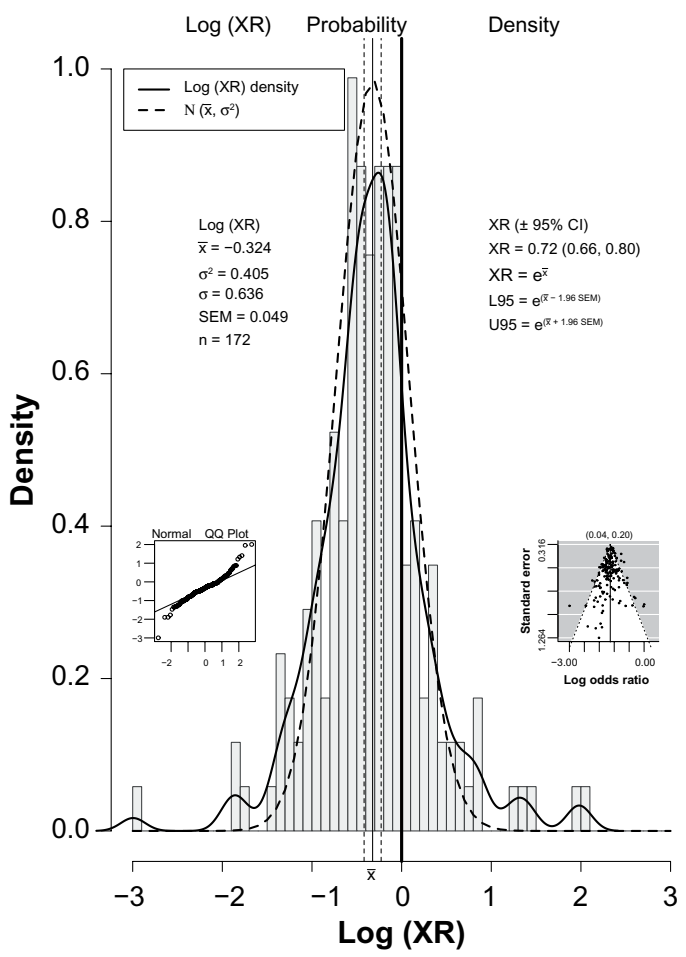

Figure 3 (A) Forest plot of 19I XRs (white dots) plus or minus their 95\% Cls (horizontal "whiskers") from 19 studies providing ratios with a reference group that did not include former drinkers. (B) Histogram of the probability density of the $\log (\mathrm{XR})$ values with a superimposed smooth probability density curve (solid line) and a superimposed normal distribution density curve (dashed line) calculated using the mean and variance of $\log (X R)$.

Notes: The $X R_{w m}$ in Figure $3 A$ is close to that seen in Figure 2. Other conventions are as for Figure 2.

Abbreviations: $\mathrm{Cl}$, confidence interval; $\mathrm{HR}$, hazard ratio; NoQuitters, no quitters; OR, odds ratio; Q-Q, quantile-quantile; RR, risk ratio; SEM, standard error of the mean; $\mathrm{XRs}$, hazard ratios, odds ratios, and risk ratios; $\mathrm{XR}_{\mathrm{wm}}$, weighted mean ratio.

indicating no difference in risk for drinkers and nondrinkers ("NoDiff"); and only 23 (5\%) were significantly greater than 1 , indicating greater risk or "worse" cognition in drinkers. These 23 ratios from 18 studies are plotted in Figure 4 and will be discussed in detail.

Of the 23 ratios in the "worse" group, twelve were associated with heavy drinking, including three $(1.58,1.59,1.93)$ for cognitive impairment from Zuccala et al ${ }^{123}$ in which subjects consumed more than $1 \mathrm{~L}$ /day of wine. The ratio of 1.80 for cognitive decline from the study in Hungary by Vincze et $\mathrm{al}^{157}$ was for "regular" (heavy) drinkers. The ratios of 2.40 for cognitive decline and 3.90 for dementia from a Finnish study by Järvenpää et a ${ }^{145}$ were both for heavy binge drinkers. The ratio of 2.50 for $\mathrm{AD}$ from Harwood et a ${ }^{134}$ was for white non-Hispanic subjects in the US consuming more than two drinks/day, which was considered heavy drinking. The ratio of 4.01 from the study in the US by Edelstein et al ${ }^{130}$ was for women drinking two drinks/day, which is considered heavy for women. The ratio of 4.99 from the study in China by Chan et a ${ }^{167}$ was from heavy drinkers ( $>4$ drinks/day). The ratio of 6.09 from the study by Barnes et $\mathrm{al}^{162}$ was for heavy drinkers
( $>2$ drinks/day). The ratios of 7.07 for dementia from Anttila et a $\mathrm{l}^{139}$ and 7.42 for dementia from Kivipelto et $\mathrm{al}^{159}$ were from subjects in Finland drinking frequently, often in binges, who also had the apolipoprotein E epsilon 4 (APOE $\varepsilon 4$ ) allele. Lastly, although not related to heavy drinking, the ratio of 3.28 for AD was from subjects in the Canadian Study on Health and Aging ${ }^{127}$ with the APOE $\varepsilon 4$ allele.

The remaining worse ratios were not clearly associated with heavy or binge drinking. The ratio of 1.46 for cognitive impairment from the study in China by Au Yeung et a ${ }^{175}$ was for light drinkers, and the same study also reported a ratio of 1.53 for ex-drinkers. The ratio of 2.34 for dementia from the study by Truelsen et al ${ }^{133}$ in Denmark was for beer drinkers compared with subjects who never or hardly ever drank beer. Similarly, the ratio of 2.47 for dementia from the study in China by Deng et al ${ }^{149}$ was for light to moderate beer drinkers. The ratio of 3.39 for vascular dementia from Yoshitake et $\mathrm{a}^{118}$ was for a broad group of drinkers in Japan in which alcohol consumption was not quantified but simply categorized into nondrinkers and drinkers. The 3.47 ratio for cognitive impairment from the study in China by Zhou et $\mathrm{al}^{138}$ was for 
Worse: $X_{\mathrm{wm}}=2.35(1.94,2.84)$

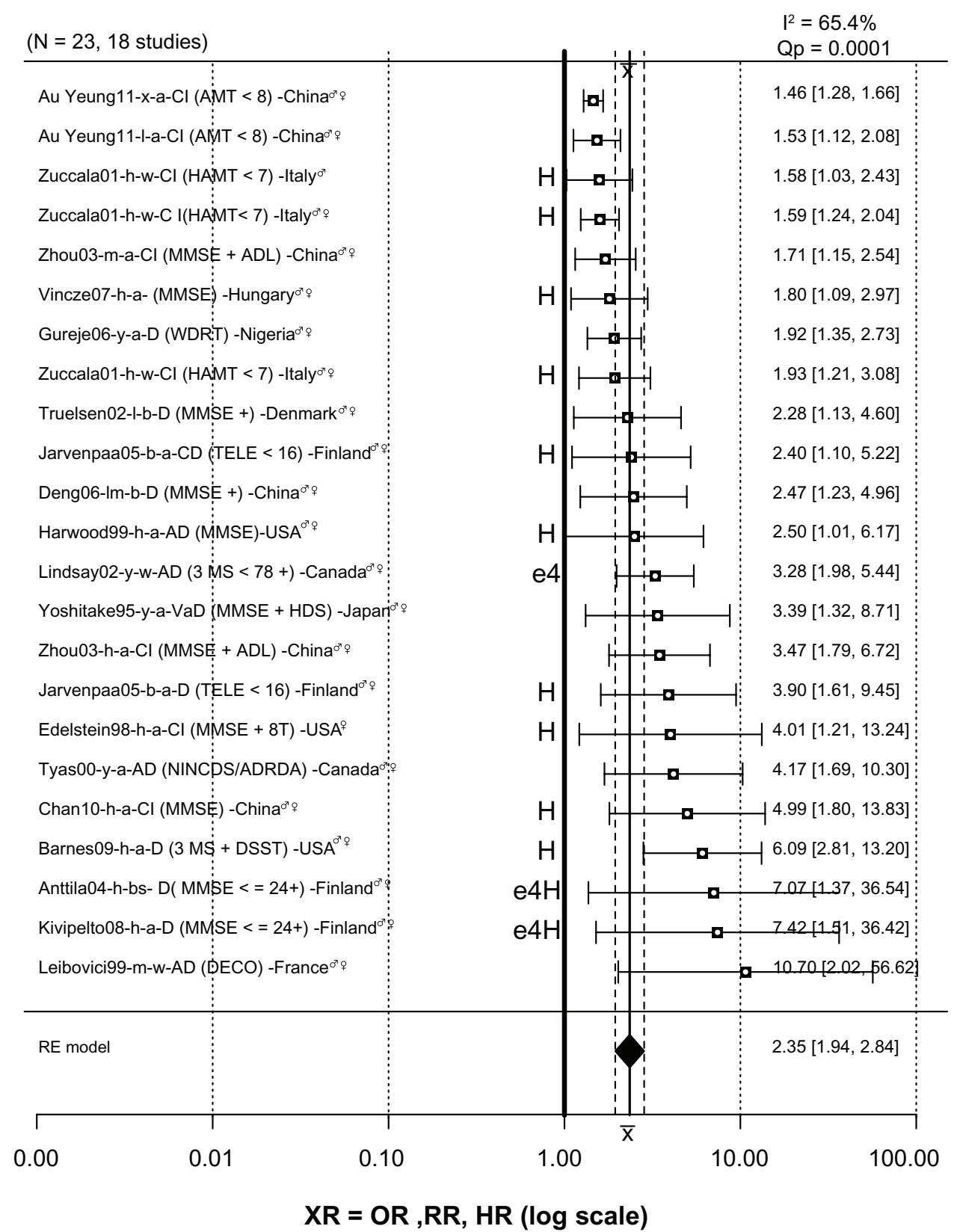

Figure 4 Forest plot of 23 XRs plus or minus their $95 \%$ Cls (horizontal "whiskers") from 18 studies providing ratios where drinkers were significantly worse than nondrinkers.

Notes: Uppercase "H" at left of vertical reference line at I indicates ratios from heavy drinkers; "e4" indicates presence of apolipoprotein E epsilon 4 allele. Other conventions as in Figure 2A. Note that the $\mathrm{XR}_{\text {wm }}$ of 2.43 ( $95 \% \mathrm{Cl}$ : $\left.1.95-3.03\right)$ is much larger than that seen in Figure 2 and is significantly greater than I.

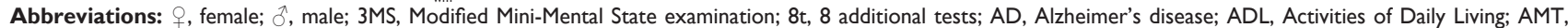
Abbreviated Mental Test; Cl, confidence interval; D, dementia; DECO, Deterioration Cognitive Observee test; DSST, Digit Symbol Substitution Test; HAMT, Hodkinson Abbreviated Mental Test; HR, hazard ratio; MMSE, Mini-Mental State Examination; MSE, mental status exam; NINCDS/ADRDA, National Institute of Neurological Communicative Disorders and Stroke/Alzheimer's Disease and Related Disorders Association criteria for AD; NoDiff, no different; OR, odds ratio; RR, risk ratio; TELE, telephone screen for cognitive impairment; WDRT, Word Delay Recall Test; $X R s$, hazard ratios, odds ratios, and risk ratios; $X_{\text {wm }}$, weighted mean ratio.

subjects consuming an unknown amount of alcohol daily; the same study reported a ratio of 1.71 for weekly consumption of an unknown amount of alcohol. The ratio of 4.17 for AD from the University of British Columbia cohort in the study in Canada by Tyas et $\mathrm{al}^{119}$ was for any amount of alcohol use.
Finally, the ratio of 10.70 for AD from the study in France by Leibovici et $\mathrm{al}^{136}$ is for moderate wine drinkers in France only after adjustment for place of residence (community or institution); before adjustment the ratio was 0.13 (95\% CI: 0.04-1.02), suggesting reduced risk. The authors explained 
this dramatic ratio change from 0.13 to 10.70 as due, at least in part, to demented and institutionalized residents being classed as nondrinkers due to drinking being forbidden in their facility and therefore inflating the number of AD cases in the nondrinkers group. Although this is a plausible explanation, it has not been replicated in other studies that included institutionalization as a covariate. For example, Huang et al ${ }^{125}$ reported an OR for AD of 0.5 (95\% CI: 0.3-0.7) in light to moderate drinkers after adjusting for age, gender, education, smoking, institutionalization (living place), and baseline MMSE score. In addition, when institutionalized subjects were excluded and the analysis repeated, the results did not change significantly. In fact, the study by McCallum et al ${ }^{184}$ reported that light to moderate alcohol significantly delayed the hazard of nursing home placement.

In summary, $13 / 23$ ratios (57\%) in the "worse" group were associated with either heavy drinking (12) or the APOE $\varepsilon 4$ allele (1). The remaining ten ratios linking light, moderate, or unknown amounts of alcohol consumption with significantly increased risk of dementia or cognitive impairment represent only $2.2 \%$ (10/446) of the total.

\section{Other questions}

Similar meta-analyses were done for a number of other questions, which will be discussed in reference to Figure 5, which presents a summary plot of the various meta-analyses carried out. As already discussed, comparing the lines labeled "All" and "Noquitter" in Figure 5 shows that there was no significant difference between the overall $\mathrm{XR}_{\mathrm{wm}}$ values of 0.77 for "All" and 0.79 for no "sick quitters" in the reference group. In addition, the 23 ratios from 18 studies in the line in Figure 5 labeled "worse" have also been discussed in detail. (For reference, the overall $\mathrm{XR}_{\mathrm{wm}}$ values for "better" and "nodiff" groups of ratios are also presented; note that the overall weighted mean for "nodiff" of 0.88 was also significantly less than 1).

Does statistical adjustment for age, education, sex, and smoking change the effect of alcohol on cognitive risk?

Only including studies with these adjustments produced no significant change in alcohol's effects, as seen for AdjAESK $(0.75)$ in Figure 5.

Moderate drinking and risk of dementia or cognitive impairment/decline

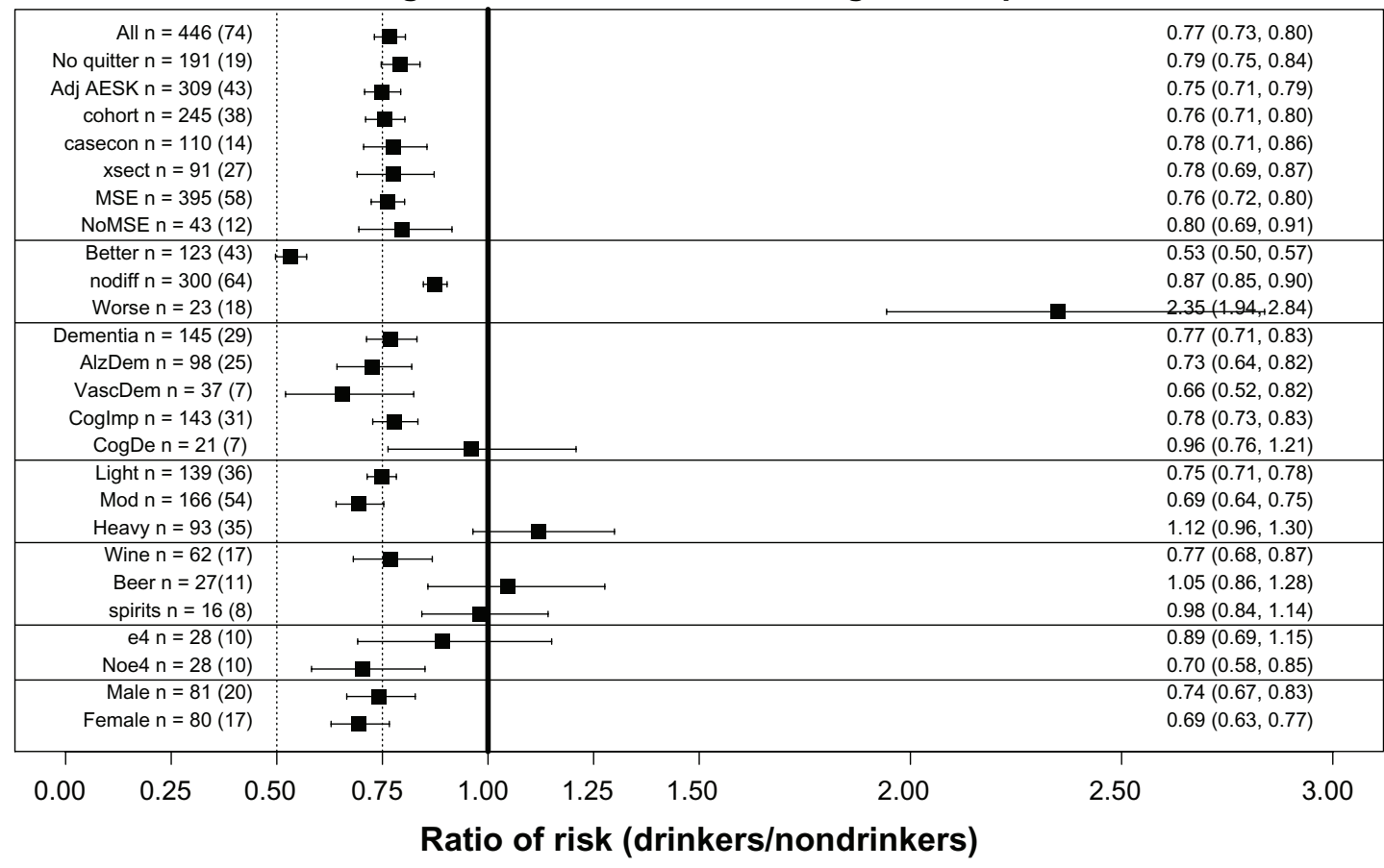

Figure 5 Overall weighted mean ratios $\left(X R_{w m}\right)$ comparing cognitive function in drinkers and nondrinkers in the various groups analyzed. Group with number of ratios (number of studies) indicated on left; $\mathrm{XR}_{\mathrm{wm}}(95 \%$ confidence interval) given on right.

Note: See text for fuller description.

Abbreviations: AdjAESK, Adjusted for Age, Education, Sex, and Smoking; AlzDem, Alzheimer's disease; casecon, case-control study; CogDec, cognitive decline; Coglmp, cognitive improvement; e4, epsilon 4; heavy, heavy drinkers; light, light drinkers; mod, moderate drinkers; MSE, mental status exam; nodiff, no different; Noe4, no epsilon 4; NoMSE, no mental status exam; Noquitter, no quitters; VascDem, vascular dementia; $\mathrm{XR}$, hazard ratio, odds ratio, and risk ratio; $\mathrm{XR}_{\mathrm{wm}}$, weighted mean ratio; xsect, cross-sectional study. 
Are there any significant differences among longitudinal cohort studies, case-control studies, or cross-sectional studies?

There was no significant difference in alcohol's effects when the three different types of epidemiological studies were considered separately, as seen for cohort (0.76), casecon (0.78), and xsect (0.78) in Figure 5.

Are there any significant differences between studies using mental status exams and those using other methods for measuring cognition?

There was no significant change in alcohol's effects when cognition was measured in these two ways, as seen for MSE (0.76) and NoMSE (0.80) in Figure 5. However, note that 90\% of the ratio studies used mental status exams in some way in their measurement of cognition, so this question must also be answered by referring to the discussion of the plot in Figure 1, which shows that mental status exams were more often associated with finding "better" cognition in drinkers, while neuropsychological tests were more often associated with finding "nodiff" in cognition between drinkers and nondrinkers.

\section{Are there different effects of moderate drinking} on general dementia, $A D$, and vascular dementia?

There were no significant differences between alcohol's effects on the different types of dementia, as seen for Dementia (0.77), AlzDem (0.73), and VascDem (0.66) in Figure 5.

\section{Are there specific effects of moderate drinking} on cognitive impairment and cognitive decline?

Figure 5 shows the risk of cognitive impairment was similar to that for All and Dementia, but the risk for cognitive decline, which was measured in only 21 ratios from seven studies, did not remain significantly less than 1.0 (see CogImp [0.78] and $\operatorname{CogDec}[0.96])$. The recent meta-analysis by Peters et $\mathrm{a}^{11}$ also failed to find a significant benefit of alcohol use against cognitive decline $(\mathrm{RR}=0.89$; 95\% CI: 0.67-1.17).

\section{Do light, moderate, and heavy drinking} have different effects on cognitive risk?

Both light and moderate drinking were associated with significantly reduced cognitive risk, while heavy drinking was associated with increased cognitive risk, as seen in Figure 5 (light [0.75], mod [0.69, and heavy [1.13]]).

Do different types of alcohol (wine, beer, and spirits) affect cognitive risk in the same way?

Wine provided a significant reduction in cognitive risk, while beer and spirits did not, as seen in Figure 5 (wine
[0.77], beer [1.05], and spirits [0.98]). Consistent with this finding, in the Washington Heights-Inwood Columbia Aging Project (WHICAP) cohort Luchsinger et a ${ }^{142}$ found a reduced risk $(\mathrm{RR}=0.45)$ of $\mathrm{AD}$ only in those consuming up to three daily servings of wine who also lacked the APOE $\varepsilon 4$ allele; there was no significant reduction of risk in those consuming beer $(\mathrm{RR}=1.47)$ and spirits $(R R=1.51)$. However, this conclusion must be qualified in two ways. First, it is based on a relatively small number of ratios from a small number of studies. Second, a number of studies explicitly looked for but did not find a difference between types of alcohol. For example, Huang et al ${ }^{125}$ found that light to moderate drinkers had a significantly reduced risk of developing dementia compared with nondrinkers $(\mathrm{RR}=0.50)$, regardless of the type of alcohol consumed. Likewise, the Rotterdam Study ${ }^{129}$ found a significantly reduced risk $(\mathrm{HR}=0.58)$ of dementia in moderate $(\leq 3$ drinks/day) drinkers of any type of alcohol. In addition, when Ruitenberg et a ${ }^{129}$ used the HR for dementia of wine drinkers as the reference (1.00), they found the HR for beer was 0.64 (95\% CI: $0.25-1.61)$ and for spirits was 1.32 (95\% CI: 0.77-2.26), yielding no significant differences between these types of alcohol. However, male and female drinkers were combined for this analysis, and the two sexes have different drinking patterns, which may have masked genuine differences among types of alcohol. ${ }^{160}$

\section{Does the APOE $\varepsilon 4$ allele alter the effect of alcohol on cognition?}

The presence of the APOE $\varepsilon 4$ allele appeared to eliminate the significantly reduced cognitive risk effect of moderate drinking, as seen for e4 (0.89) and noe4 (0.70) in Figure 5. Consistent with this conclusion, in the WHICAP cohort Luchsinger et $\mathrm{a}^{142}$ found a reduced risk $(\mathrm{RR}=0.45)$ of $\mathrm{AD}$ only in those without the APOE $\varepsilon 4$ allele who were drinking up to three daily servings of wine. Similarly, in Canada, Lindsay et $\mathrm{al}^{127}$ reported an increased risk $(\mathrm{OR}=3.28)$ for $\mathrm{AD}$ for drinkers (any amount) with the APOE $\varepsilon 4$ allele. Likewise, the study in Finland by Anttila et a ${ }^{139}$ found that infrequent ( $<1$ drink/month) "binge" drinkers without the APOE $\varepsilon 4$ had a nonsignificantly reduced risk of dementia $(\mathrm{RR}=0.45)$ compared with nondrinkers, while infrequent "binge" drinkers with APOE $\varepsilon 4$ had a large and significant increase in the risk of dementia $(R R=2.30)$. The same study reported an increased risk $(\mathrm{OR}=7.07)$ for dementia in heavy (frequent) drinkers with the APOE $\varepsilon 4$ allele. Furthermore, Harwood et $\mathrm{al}^{185}$ reported that those with the APOE $\varepsilon 4$ allele have an earlier onset of AD by an average of 2.6 (for one $\varepsilon 4$ ) or 5.3 (for two $\varepsilon 4 \mathrm{~s}$ ) years. 
In contrast, the Rotterdam Study ${ }^{129}$ reported the HR was reduced in subjects with the APOE $\varepsilon 4$ allele, but the sample and the difference were both small. Likewise, Carmelli et al ${ }^{132}$ found that light drinking ( $\leq 1$ drink/day) by white male veterans was associated with a significantly reduced risk $(\mathrm{OR}=0.60)$ of poor cognitive function using the MMSE, particularly among those with the APOE $\varepsilon 4$ allele. Similarly, Tanaka et al ${ }^{131}$ reported an OR of $1.60(1.00,2.55)$ for AD in moderate drinkers without the APOE $\varepsilon 4$ allele.

Lastly, no effect of APOE $\varepsilon 4$ was found in the Nurses' Health Study ${ }^{147}$ in which women drinking moderately (1 drink/day) had a significantly reduced risk of cognitive decline $(\mathrm{RR}=0.85)$, as measured by being in the worst $10 \%$ of the distribution of decline on the TICS.

In conclusion, although analysis found that the presence of APOE $\varepsilon 4$ allele eliminated any significant "protective" effect of moderate ethanol on cognitive risk, a number of other studies have found an opposite effect and our results are based on a relatively small number of ratios from just ten studies, leaving this question unsettled.

\section{Does the sex of the drinker alter the effect of alcohol on cognition?}

There was no difference in alcohol's effects between sexes, as seen in Figure 5 (male, 0.74; female, 0.69), despite the fact that men and women have very different drinking patterns. In general, male drinkers drink more than female drinkers and prefer beer and spirits, while female drinkers prefer wine. $^{.7,89,129,133,137,140}$

\section{Does the effect of alcohol on cognition vary with country?}

The beneficial association of moderate drinking with reduced cognitive risk was found in almost all countries studied (see Figure 6). These analyses were first done using all the ratios from each country, including ratios from heavy drinkers or those carrying the APOE $\varepsilon 4$ allele. This "all ratios" approach found a significant benefit in the US (USA), the United Kingdom (UK), France, Italy, Spain, Germany, the Netherlands, Sweden, Australia, Brazil, and Korea (as seen above the heavy dashed line running horizontally in Figure 6), although for some countries (those below the same line in Figure 6) the approach failed to find a significant benefit. However, if ratios from heavy drinkers or those carrying the APOE $\varepsilon 4$ allele were excluded, the country's ratio then showed a significant benefit. For example, compare the canada and canada-ne4 (no \&4) lines, or the finland and finlne $4 \mathrm{~h}$ (no $\varepsilon 4$ and no heavy drinkers) lines. In Denmark the initial analysis (denmark) showed no benefit, but a benefit was seen if only wine drinkers were included (denmark-wn). Similarly, China and Taiwan (chinat) initially showed no significant benefit, but if heavy drinkers were excluded (chinat-nh) a significant benefit was found. However, this strategy did not succeed in identifying a significant benefit for Hungary (compare hungary and hungary-nh lines) or for Japan (compare japan and japan-nh lines). However, in the case of Japan it should be noted that two studies of Japanese Americans (japan-amer) ${ }^{14,148}$ did find a significant benefit of alcohol, suggesting failure to find a significant benefit in the studies in Japan may not have a genetic basis. In addition, one "no ratio" study of Japanese Americans found better cognition in moderate drinkers. ${ }^{79}$ No overall benefit was seen in two studies from Nigeria, although one of the studies did have an OR significantly lower than $1^{151}$ while the other did not ${ }^{150}$ (solid dots indicate these two ORs in Figure 6). Two studies of African-Americans did find nonsignificantly reduced risk in drinkers. ${ }^{135,151}$ Lastly, one study in Greece ${ }^{128}$ reported a nonsignificantly reduced risk in drinkers.

The absence of studies from Eastern Europe and Russia is notable, but a 2009 paper with a large number of Russian authors stated: "To our knowledge, there are no published or ongoing population-based studies designed to estimate the prevalence of $\mathrm{AD}$ and other forms of dementia in Russia." 186

\section{General discussion}

\section{Summary}

The history of research on moderate drinking and cognition can be divided into two eras: 1977-1997 and 1998-present. Phase I (1977-1997) was the era of neuropsychological evaluation involving mostly young to middle-aged (18-50 years old) subjects. Although initial studies indicated moderate drinking impaired cognition, many later studies failed to confirm this, instead finding no difference in cognition between drinkers and nondrinkers. Phase II (1998-present) was and is the era of mental status exam evaluation involving mostly older ( $\geq 55$ years old) subjects. These studies overwhelmingly found that moderate drinking either reduced or had no effect on the risk of dementia or cognitive impairment.

When all the ratios of risk from all the studies in phase II providing such ratios are entered into a comprehensive metaanalysis, the average ratio of risk for cognitive risk (dementia or cognitive impairment/decline) associated with moderate "social" drinking of alcohol is 0.77 , with nondrinkers as the reference group. This value is similar to the values obtained by two recent and much more selective meta-analyses (Anstey et $\mathrm{al}^{12}$ overall $\mathrm{RR}=0.74$; Peters et $\mathrm{al}^{11}$ overall $\mathrm{RR}=0.73$ ). 


\section{Geography: Moderate drinking and risk of dementia or cognitive impairment/decline}

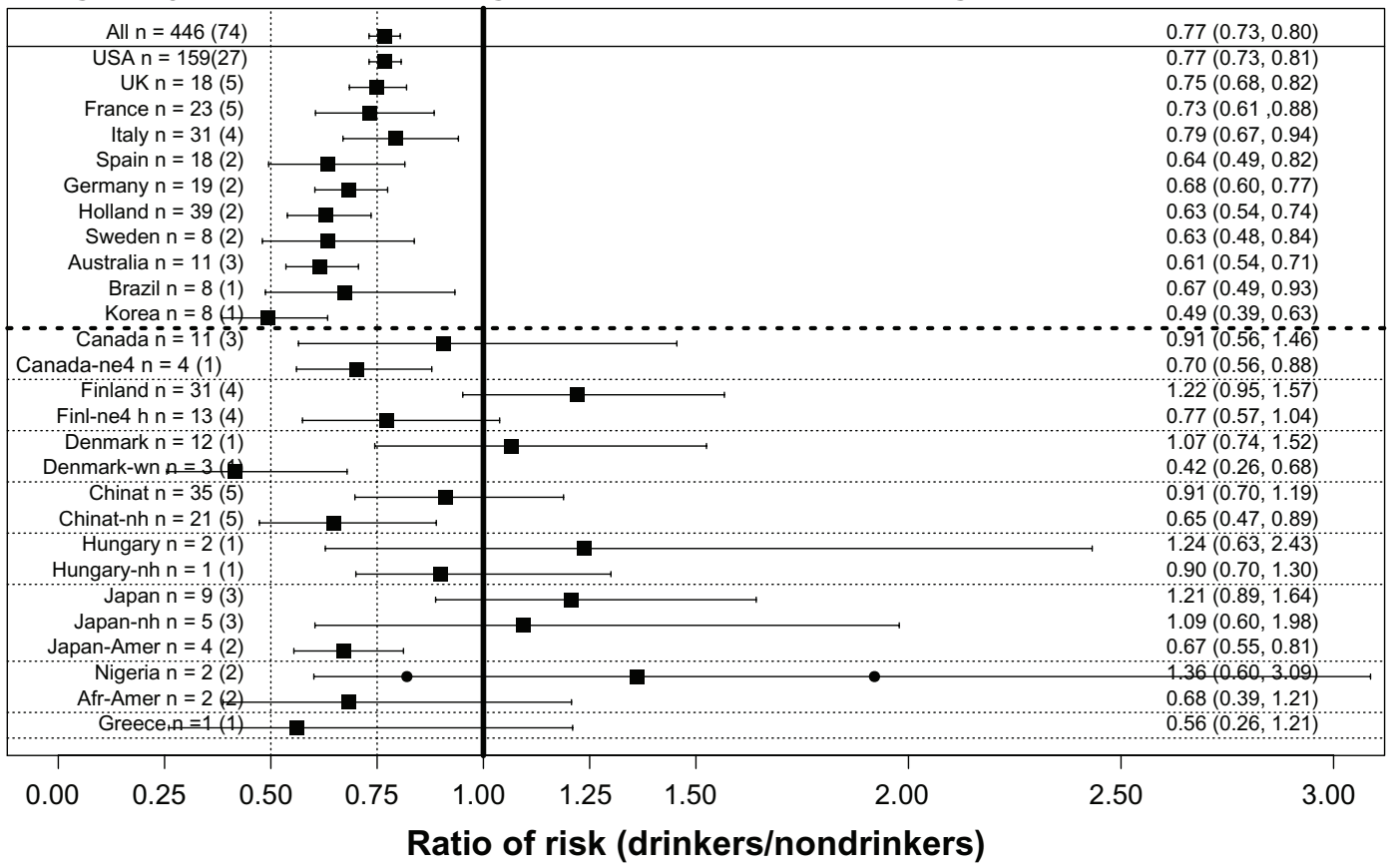

Figure 6 Overall weighted mean ratios $\left(\mathrm{XR}_{\mathrm{wm}}\right)$ comparing cognitive risk in drinkers and nondrinkers by country. Country with number of ratios (number of studies) indicated on left; $X R_{w m}(95 \%$ confidence interval) given on right.

Abbreviations: afr-amer, African-Americans; australia, Australia; brazil, Brazil; canada, Canada; canada-ne4, Canada, no epsilon 4; chinat, China and Taiwan; chinat-nh, China and Taiwan, no heavy drinkers; denmark, Denmark; denmark-wn, Denmark, wine drinkers; finland, Finland; finl-ne4h, Finland, no epsilon 4, no heavy drinkers; france, France; germany, Germany; greece, Greece; holland, the Netherlands; hungary, Hungary; hungary-nh, Hungary, no heavy drinkers; italy, Italy; japan, Japan; japan-amer, Japanese Americans; japan-nh, Japan, no heavy drinkers; korea, Korea; nigeria, Nigeria; spain, Spain; sweden, Sweden; UK, United Kingdom; USA, United States of America; XR, hazard ratio, odds ratio, and risk ratio.

The benefit of moderate drinking applied to all forms of dementia and to cognitive impairment, but no significant benefit against cognitive decline was found.

Both light and moderate drinking provided a similar benefit, but heavy drinking was associated with nonsignificantly higher cognitive risk for dementia and cognitive impairment.

Although the meta-analysis also indicated that wine was better than beer or spirits, this was based on a relatively small number of studies because most studies did not distinguish among these different types of alcohol. Furthermore, a number of the studies that did make this distinction reported no difference between the effects of these different types of alcohol. Therefore, at present this question remains unanswered.

Analysis also showed the presence of the APOE $\varepsilon 4$ allele eliminated the benefit of moderate drinking. However, the analysis was based on a relatively small number of studies, and several other studies have found the opposite effect. Further studies are necessary to settle this question.

The benefit of moderate alcohol was seen in both men and women, although the pattern of drinking is very different between the two sexes, with male drinkers drinking much more than female drinkers and women tending to prefer wine over other forms of alcohol. ${ }^{129,160}$
Overall, light to moderate drinking does not appear to impair cognition in younger subjects and actually seems to reduce the risk of dementia and cognitive decline in older subjects. This basic finding was the same in many different countries, particularly when results from heavy drinkers or subjects with the APOE $\varepsilon 4$ allele were excluded.

\section{Mental status exams}

The MMSE, ${ }^{187}$ which has been the "workhorse" of the mental status era, is considered to have several weaknesses, including relatively poor assessment of executive function and floor and ceiling effects because it has only 30 possible points. ${ }^{188,189}$ These limitations were reviewed in a recent meta-analysis of the MMSE, which concluded it was best for "ruling-out a diagnosis of dementia in community and primary care" and that "for all other uses it should be combined with or replaced by other methods." 190 Nonetheless, the very fact of the MMSE's widespread use means that "the same ruler" has been applied to measuring cognition in many studies, making the consistent results of a benefit of moderate drinking plausible. In addition, in about $60 \%$ of the 67 studies with and without ratios that used some type of mental status exam, the status exam was combined with one or more 
other measurements of cognition, making the judgment of dementia or cognitive impairment more reliable.

\section{Comparison with other cognitive risk reducers}

How does an overall ratio of 0.77 compare with ratios of risk associated with other "treatments" or activities that have shown some benefit against dementia and cognitive decline? Those who eat a Mediterranean diet - which includes high intake of vegetables, fruits, cereals, fish, olive oil, and wine - have an OR for dementia of 0.60. ${ }^{191}$ Similarly, $\mathrm{Gu}$ et $\mathrm{al}^{192}$ reported that the HR for AD was 0.62 (95\% CI: 0.43-0.89) after multivariable adjustment for subjects in the highest third of conformity to a specific dietary pattern associated with reduced AD risk. Likewise, more years of education and the associated fuller participation in social and intellectual life ${ }^{193}$ provide a benefit of similar magnitude (overall RR of 0.84 ), perhaps by producing a "cognitive reserve" that results in a more gradual rate of cognitive decline. ${ }^{194}$ Gardening has also been associated with a reduced risk $(\mathrm{HR}=0.64)$ of $\mathrm{AD} .{ }^{152}$ Therefore, the reduced cognitive risk from moderate drinking is similar in size to the reduced risk associated with other factors.

\section{Other beneficial outcomes of moderate drinking}

Mukamal et al ${ }^{195}$ found that low to moderate alcohol consumption (5-30 g/day) further reduced the risk $(\mathrm{OR}=0.38$; 95\% CI: 0.16-0.89) of myocardial infarction in men (8867 subjects), even if they were also nonsmokers who were active $\geq 30 \mathrm{~min} /$ day and had a body mass index of $<25$. Similarly, in the Healthy Aging: a Longitudinal study in Europe project, low to moderate alcohol consumption was found to have a similarly beneficial effect on risk of mortality $(\mathrm{HR}=0.78)$ to a Mediterranean diet $(\mathrm{HR}=0.77)$, physical activity $(\mathrm{HR}=0.63)$, and nonsmoking $(\mathrm{HR}=0.65)$, with the combination of all four beneficial factors reducing the risk of mortality to $0.35 .{ }^{196}$ Imhof et al ${ }^{197}$ found that low to moderate drinking reduced a variety of biomarkers of inflammation, including C-reactive protein, fibrinogen, white blood cell count, and plasma viscosity. Britton et al ${ }^{198}$ found that a cardioprotective benefit of moderate drinking was found among those with poor health behaviors (little exercise, poor diet, and smoking), but no additional cardioprotective benefit of alcohol was found in those with the healthiest behavior profile. French and Zavala ${ }^{199}$ found that current moderate drinkers had the highest odds $(\mathrm{OR}=1.27$ for men, $\mathrm{OR}=2.03$ for women $)$ of reporting above-average health status compared with nondrinkers.
Karlamangla et $\mathrm{al}^{200}$ found that light to moderate drinking was associated with a reduced risk for incident disability or death over 5 years compared with abstention $(\mathrm{OR}=0.77)$. Tien et $\mathrm{al}^{201}$ found that low to moderate blood alcohol level at the time of a traumatic brain injury is associated with reduced risk of mortality (OR $=0.76$; 95\% CI: 0.52-0.98). Overall, then, the reduced cognitive risk associated with moderate drinking is comparable with the reduced risk for death, cardiovascular disease, and other morbidities.

\section{Conclusion}

Heavy drinking ( $>3-4$ drinks/day) is associated with an increased risk of dementia and cognitive impairment, in addition to all the other horrible and devastating consequences of alcohol abuse and alcoholism for the individual and their family and friends, and society in general. However, light to moderate drinking ( $\leq 2 \mathrm{drinks} /$ day for men, $\leq 1 \mathrm{drink} /$ day for women) by adults does not increase the risk of dementia, cognitive decline, or cognitive impairment - a conclusion also reached by a recent comprehensive review. ${ }^{13}$ In fact, notwithstanding the conclusion in a recent article that "no evidence of even moderate scientific quality exists to support the association of any modifiable factor ... with reduced risk for Alzheimer disease,"202 there is substantial evidence that light to moderate drinking (as defined in the National Institute on Alcohol Abuse and Alcoholism's position paper on moderate drinking ${ }^{203}$ ), particularly of wine, reduces the risk of dementia and cognitive impairment.

\section{Acknowledgments}

Support of the authors' research by NIH (AA013568) is acknowledged.

\section{Disclosure}

The authors report no conflicts of interest in this work.

\section{References}

1. Belmadani A, Kumar S, Schipma M, et al. Inhibition of amyloid-betainduced neurotoxicity and apoptosis by moderate ethanol preconditioning. Neuroreport. 2004;15:2093-2096.

2. Golde TE. Alzheimer disease therapy: can the amyloid cascade be halted? J Clin Invest. 2003;111:11-18.

3. Collins MA, Neafsey EJ, Mukamal KJ, et al. Alcohol in moderation, cardioprotection, and neuroprotection: epidemiological considerations and mechanistic studies. Alcohol Clin Exp Res. 2009;33:206-219.

4. Collins MA, Neafsey EJ, Wang K, et al. Moderate ethanol preconditioning of rat brain cultures engenders neuroprotection against dementia-inducing neuroinflammatory proteins: possible signaling mechanisms. Mol Neurobiol. 2010;41:420-425.

5. Mitchell RM, Neafsey EJ, Collins MA. Essential involvement of the NMDA receptor in ethanol preconditioning-dependent neuroprotection from amyloid-beta in vitro. J Neurochem. 2009;111:580-588. 
6. Sivaswamy S, Neafsey EJ, Collins MA. Neuroprotective preconditioning of rat brain cultures with ethanol: potential transduction by $\mathrm{PKC}$ isoforms and focal adhesion kinase upstream of increases in effector heat shock proteins. Eur J Neurosci. 2010;32:1800-1812.

7. Yamaguchi T, Dayton CB, Ross CR, et al. Late preconditioning by ethanol is initiated via an oxidant-dependent signaling pathway. Free Radic Biol Med. 2003;34:365-376.

8. Wang Q, Sun AY, Simonyi A, et al. Ethanol preconditioning protects against ischemia/reperfusion-induced brain damage: role of NADPH oxidase-derived ROS. Free Radic Biol Med. 2007;43:1048-1060.

9. Peele S, Brodsky A. Exploring psychological benefits associated with moderate alcohol use: a necessary corrective to assessments of drinking outcomes? Drug Alcohol Depend. 2000;60:221-247.

10. Ferreira MP, Weems MK. Alcohol consumption by aging adults in the United States: health benefits and detriments. J Am Diet Assoc. 2008;108:1668-1676.

11. Peters R, Peters J, Warner J, et al. Alcohol, dementia and cognitive decline in the elderly: a systematic review. Age Ageing. 2008;37: 505-512.

12. Anstey KJ, Mack HA, Cherbuin N. Alcohol consumption as a risk factor for dementia and cognitive decline: meta-analysis of prospective studies. Am J Geriatr Psychiatry. 2009;17:542-555.

13. Panza F, Capurso C, D'Introno A, et al. Alcohol drinking, cognitive functions in older age, predementia, and dementia syndromes. J Alzheimers Dis. 2009;17:7-31.

14. Pinder RM, Sandler M. Alcohol, wine and mental health: focus on dementia and stroke. J Psychopharmacol. 2004;18:449-456.

15. Brust JC. Ethanol and cognition: indirect effects, neurotoxicity and neuroprotection: a review. Int J Environ Res Public Health. 2010;7: $1540-1557$.

16. Lee Y, Back JH, Kim J, et al. Systematic review of health behavioral risks and cognitive health in older adults. Int Psychogeriatr. 2010;22: 174-187.

17. Solfrizzi V, Panza F, Frisardi V, et al. Diet and Alzheimer's disease risk factors or prevention: the current evidence. Expert Rev Neurother. 2011;11:677-708

18. Seux ML, Thijs L, Forette F, et al. Correlates of cognitive status of old patients with isolated systolic hypertension: the Syst-Eur Vascular Dementia Project. J Hypertens. 1998;16:963-969.

19. Sistrom CL, Garvan CW. Proportions, odds, and risk. Radiology. 2004; 230:12-19.

20. Holcomb WL, Chaiworapongsa T, Luke DA, et al. An odd measure of risk: use and misuse of the odds ratio. Obstet Gynecol. 2001;98: 685-688.

21. Hirtz D, Thurman DJ, Gwinn-Hardy K, et al. How common are the "common" neurologic disorders? Neurology. 2007;68:326-337.

22. Solfrizzi V, Panza F, Colacicco AM, et al. Vascular risk factors, incidence of MCI, and rates of progression to dementia. Neurology. 2004;63:1882-1891.

23. Glass GV. Primary, secondary, and meta-analysis of research. Educational Researcher. 1976;5:3-8.

24. Durlak JA, Lipsey MW. A practitioner's guide to meta-analysis. Am J Comm Pschol. 1991;19:291-332.

25. Stroup DF, Berlin JA, Morton SC, et al. Meta-analysis of observational studies in epidemiology: a proposal for reporting; Meta-analysis Of Observational Studies in Epidemiology (MOOSE) group. JAMA. 2000; 283:2008-2012.

26. Glass GV. Meta-analysis at 25. 2000 Jan. Available from: http://www. gvglass.info/papers/meta25.html. Accessed July 25, 2011.

27. Engels EA, Schmid CH, Terrin N, et al. Heterogeneity and statistical significance in meta-analysis: an empirical study of 125 meta-analyses. Stat Med. 2000;19:1707-1728.

28. Higgins JP, Thompson SG. Quantifying heterogeneity in a meta-analysis. Stat Med. 2002;21:1539-1558.

29. Huedo-Medina TB, Sáchez-Meca J, Marín-Martínez F, et al. Assessing heterogeneity in meta-analysis: Q statistic or I2 index? Psychol Methods. 2006;11:193-206.
30. Bland JM, Altman DG. Statistics notes: the odds ratio. BMJ. 2000;320: 1468.

31. Egger M, Smith G Davey, Schneider M, et al. Bias in meta-analysis detected by a simple, graphical test. BMJ. 1997;315:629-634.

32. Lau J, Ioannidis JP, Terrin N, et al. The case of the misleading funnel plot. BMJ. 2006;333:597-600.

33. Begg CB, Mazumdar M. Operating characteristics of a rank correlation test for publication bias. Biometrics. 1994;50:1088-1101.

34. R Development Core Team. $R$ : A language and environment for statistical computing. Vienna: R Foundation for Statistical Computing; 2011.

35. Parker ES, Noble EP. Alcohol consumption and cognitive functioning in social drinkers. J Stud Alcohol. 1977;38:1224-1232.

36. Ryback RS. The continuum and specificity of the effects of alcohol on memory: a review. Q J Stud Alcohol. 1971;32:995-1016.

37. Parsons OA, Nixon SJ. Cognitive functioning in sober social drinkers: a review of the research since 1986. J Stud Alcohol. 1998;59:180-190.

38. Parsons OA. Cognitive functioning in sober social drinkers: a review and critique. J Stud Alcohol. 1986;47:101-114.

39. Parker ES, Parker DA, Harford TC. Specifying the relationship between alcohol use and cognitive loss: the effects of frequency of consumption and psychological distress. J Stud Alcohol. 1991;52:366-373.

40. Parker DA, Parker ES, Brody JA, et al. Alcohol use and cognitive loss among employed men and women. Am J Public Health. 1983;73: 521-526.

41. Schinka JA, Belanger H, Mortimer JA, et al. Effects of the use of alcohol and cigarettes on cognition in elderly African American adults. J Int Neuropsychol Soc. 2003;9:690-697.

42. Schinka JA, Vanderploeg RD, Rogish M, et al. Effects of the use of alcohol and cigarettes on cognition in elderly adults. J Int Neuropsychol Soc. 2002;8:811-818.

43. Parker ES, Parsons OA, Fabian MS. Comments on "cognitive functioning in men social drinkers: a replication study". J Stud Alcohol. $1982 ; 43: 178-182$.

44. Parker ES, Birnbaum IM, Boyd RA, et al. Neuropsychologic decrements as a function of alcohol intake in male students. Alcohol Clin Exp Res. 1980;4:330-334.

45. Birnbaum IM, Taylor TH, Parker ES. Alcohol and sober mood state in female social drinkers. Alcohol Clin Exp Res. 1983;7:362-368.

46. Jones MK, Jones BM. The relationship of age and drinking habits to the effects of alcohol on memory in women. J Stud Alcohol. 1980;41:179-186

47. Cala LA, Jones B, Burns P, et al. Results of computerized tomography, psychometric testing and dietary studies in social drinkers, with emphasis on reversibility after abstinence. Med J Aust. 1983;2: 264-269.

48. MacVane J, Butters N, Montgomery K, et al. Cognitive functioning in men social drinkers: a replication study. J Stud Alcohol. 1982;43: 81-95.

49. Hannon R, Butler CP, Day CL, et al. Alcohol use and cognitive functioning in men and women college students. Recent Dev Alcohol. $1985 ; 3: 241-252$.

50. Hannon R, Day CL, Butler AM, et al. Alcohol consumption and cognitive functioning in college students. J Stud Alcohol. 1983;44:283-298.

51. Bergman H. Cognitive deficits and morphological cerebral changes in a random sample of social drinkers. Recent Dev Alcohol. 1985;3: 265-276.

52. Hunt E, Coggan P, Berg C, et al. The effects of social drinking practices on cognitive performance. Unpublished manuscript, Department of Psychology, University of Washington; 1984.

53. Parsons OA. Are there nonacute effects of social drinking on mental functioning? Unpublished manuscript presented at: the 13th International Medical Advisory Conference; 1984; Cambridge MA (cited in Parsons 1986 review).

54. Jones-Saumty DJ, Zeiner AR. Psychological correlates of drinking behavior in social drinker college students. Alcohol Clin Exp Res. 1985;9:158-163. 
55. Martin E, Sher KF, Wood PK. Substance use and neuropsychological test performance in college students. Paper presented at: the annual meeting of the Association for the Advancement of Behavior Therapy; 1991; New York.

56. Carey KB, Maisto SA. Effect of a change in drinking pattern on the cognitive function of female social drinkers. J Stud Alcohol. 1987;48: 236-242.

57. Farmer ME, White LR, Abbott RD, et al. Blood pressure and cognitive performance: the Framingham Study. Am J Epidemiol. 1987;126: 1103-1114.

58. Page RD, Cleveland MF. Cognitive dysfunction and aging among male alcoholics and social drinkers. Alcohol Clin Exp Res. 1987;11: 376-384.

59. Nichols JM, Martin F, Kirkby KC. A comparison of the effect of lorazepam on memory in heavy and low social drinkers. Psychopharmacology (Berl). 1993;112:475-482.

60. Mangione CM, Seddon JM, Cook EF, et al. Correlates of cognitive function scores in elderly outpatients. J Am Geriatr Soc. 1993;41: 491-497.

61. Bowden SC. Brain impairment in social drinkers? no cause for concern. Alcohol Clin Exp Res. 1987;11:407-410.

62. Fox AM, Michie PT, Coltheart M, et al. Memory functioning in social drinkers: a study of event-related potentials. Alcohol Alcohol. 1995;30 $303-310$.

63. Goodwin JS, Sanchez CJ, Thomas P, et al. Alcohol intake in a healthy elderly population. Am J Public Health. 1987;77:173-177.

64. Emmerson RY, Dustman RE, Heil J, et al. Neuropsychological performance of young nondrinkers, social drinkers, and long- and short-term sober alcoholics. Alcohol Clin Exp Res. 1988;12:625-629.

65. Alterman AI, Hall JG. Effects of social drinking and familial alcoholism risk on cognitive functioning: null findings. Alcohol Clin Exp Res. 1989;13:799-803.

66. Waugh M, Jackson M, Fox GA, et al. Effect of social drinking on neuropsychological performance. Br J Addict. 1989;84:659-667.

67. Bates ME, Tracy JI. Cognitive functioning in young "social drinkers": is there impairment to detect? J Abnorm Psychol. 1990;99:242-249.

68. Salamé P. The effects of alcohol on learning as a function of drinking habits. Ergonomics. 1991;34:1231-1241.

69. Scherr PA, Albert MS, Funkenstein HH, et al. Correlates of cognitive function in an elderly community population. Am J Epidemiol. 1988; 128:1084-1101.

70. Arbuckle TY, Chaikelson JS, Gold DP. Social drinking and cognitive functioning revisited: the role of intellectual endowment and psychological distress. J Stud Alcohol. 1994;55:352-361.

71. Christian JC, Reed T, Carmelli D, et al. Self-reported alcohol intake and cognition in aging twins. J Stud Alcohol. 1995;56:414-416.

72. Carmelli D, Swan GE, LaRue A, et al. Correlates of change in cognitive function in survivors from the Western Collaborative Group Study. Neuroepidemiology. 1997;16:285-295.

73. Cerhan JR, Folsom AR, Mortimer JA, et al. Correlates of cognitive function in middle-aged adults: Atherosclerosis Risk in Communities (ARIC) Study Investigators. Gerontology. 1998;44:95-105.

74. Dent OF, Sulway MR, Broe GA, et al. Alcohol consumption and cognitive performance in a random sample of Australian soldiers who served in the Second World War. BMJ. 1997;314:1655-1657.

75. Broe GA, Creasey H, Jorm AF, et al. Health habits and risk of cognitive impairment and dementia in old age: a prospective study on the effects of exercise, smoking and alcohol consumption. Aust NZJ Public Health. 1998;22:621-623.

76. Nixon SJ. Alcohol, aging, and cognition. In: Gomberg ESL, Hegedus AM, Zucker RA, editors. Alcohol problems and aging. NIAAA Research Monograph No. 33, NIH Publication No. 98-4163. Bethesda, MD: National Institute on Alcohol Abuse and Alcoholism; 1998:213-227.

77. Elias PK, Elias MF, D'Agostino RB, et al. Alcohol consumption and cognitive performance in the Framingham Heart Study. Am JEpidemiol. 1999; 150:580-589.
78. Sands ML, Schwartz AV, Brown BW, et al. Relationship of neurological function and age in older women: the study of osteoporotic fractures. Neuroepidemiology. 1998;17:318-329.

79. Bond GE, Burr R, McCurry SM, et al. Alcohol, aging, and cognitive performance in a cohort of Japanese Americans aged 65 and older: the Kame project. Int Psychogeriatr. 2001;13:207-223.

80. Kalmijn S, van Boxtel MP, Verschuren MW, et al. Cigarette smoking and alcohol consumption in relation to cognitive performance in middle age. Am J Epidemiol. 2002;156:936-944.

81. Elwood PC, Gallacher JE, Hopkinson CA, et al. Smoking, drinking, and other life style factors and cognitive function in men in the Caerphilly cohort. J Epidemiol Community Health. 1999;53:9-14.

82. Leroi I, Sheppard JM, Lyketsos CG. Cognitive function after 11.5 years of alcohol use: relation to alcohol use. Am J Epidemiol. 2002;156: $747-752$.

83. Wang L, van Belle G, Kukull WB, et al. Predictors of functional change: a longitudinal study of nondemented people aged 65 and older. $J \mathrm{Am}$ Geriatr Soc. 2002;50:1525-1534.

84. Bond GE, Burr R, Rice MM, et al. Alcohol, aging, and cognitive performance: a cross-cultural comparison. J Aging Health. 2003;15: 371-390.

85. Reid MC, Maciejewski PK, Hawkins KA, et al. Relationship between alcohol consumption and Folstein mini-mental status examination scores among older cognitively impaired adults. J Geriatr Psychiatry Neurol. 2002;15:31-37.

86. Schinka JA, Vanderploeg RD, Rogish M, et al. Effects of alcohol and cigarette use on cognition in middle-aged adults. $J$ Int Neuropsychol Soc. 2002;8:683-690.

87. Zimmerman T, McDougall GJ, Becker H. Older women's cognitive and affective response to moderate drinking. Int J Geriatr Psychiatry. 2004;19:1095-1102.

88. Lindeman RD, Wayne SJ, Baumgartner RN, et al. Cognitive function in drinkers compared to abstainers in the New Mexico elder health survey. J Gerontol A Biol Sci Med Sci. 2005;60:1065-1070.

89. Krahn D, Freese J, Hauser R, et al. Alcohol use and cognition at midlife: the importance of adjusting for baseline cognitive ability and educational attainment. Alcohol Clin Exp Res. 2003;27:1162-1166.

90. Yonker JE, Nilsson LG, Herlitz A, et al. Sex differences in spatial visualization and episodic memory as a function of alcohol consumption. Alcohol Alcohol. 2005;40:201-207.

91. Rodgers B, Windsor TD, Anstey KJ, et al. Non-linear relationships between cognitive function and alcohol consumption in young, middleaged and older adults: the PATH Through Life Project. Addiction. 2005; 100:1280-1290.

92. Richards M, Hardy R, Wadsworth ME. Alcohol consumption and midlife cognitive change in the British 1946 birth cohort study. Alcohol Alcohol. 2005;40:112-117.

93. Stott DJ, Falconer A, Kerr GD, et al. Does low to moderate alcohol intake protect against cognitive decline in older people? J Am Geriatr Soc. 2008;56:2217-2224

94. Reid MC, Van Ness PH, Hawkins KA, et al. Light to moderate alcohol consumption is associated with better cognitive function among older male veterans receiving primary care. J Geriatr Psychiatry Neurol. 2006;19:98-105.

95. Cooper $\mathrm{C}$, Bebbington $\mathrm{P}$, Meltzer H, et al. Alcohol in moderation, premorbid intelligence and cognition in older adults: results from the Psychiatric Morbidity Survey. J Neurol Neurosurg Psychiatry. 2009;80: 1236-1239.

96. McDougall GJ, Becker H, Areheart KL. Older males, cognitive function, and alcohol consumption. Issues Ment Health Nurs. 2006;27: 337-353.

97. Andersen K, Lolk A, Martinussen T, et al. Very mild to severe dementia and mortality: a 14-year follow-up - the Odense study. Dement Geriatr Cogn Disord. 2010;29:61-67.

98. Ngandu T, Helkala EL, Soininen H, et al. Alcohol drinking and cognitive functions: findings from the Cardiovascular Risk Factors Aging and Dementia (CAIDE) Study. Dement Geriatr Cogn Disord. 2007;23:140-149. 
99. Caspers K, Arndt S, Yucuis R, et al. Effects of alcohol- and cigarette-use disorders on global and specific measures of cognition in middle-age adults. J Stud Alcohol Drugs. 2010;71:192-200.

100. Lang I, Wallace RB, Huppert FA, et al. Moderate alcohol consumption in older adults is associated with better cognition and well-being than abstinence. Age Ageing. 2007;36:256-261.

101. Sabia S, Guéguen A, Berr C, et al. High alcohol consumption in middle-aged adults is associated with poorer cognitive performance only in the low socio-economic group: results from the GAZEL cohort study. Addiction. 2011;106:93-101.

102. Townsend MK, Devore E, Kang JH, et al. The relation between moderate alcohol consumption and cognitive function in older women with type 2 diabetes. Diabetes Res Clin Pract. 2009;85:322-327.

103. Xu G, Liu X, Yin Q, et al. Alcohol consumption and transition of mild cognitive impairment to dementia. Psychiatry Clin Neurosci. 2009; 63:43-49.

104. Arntzen KA, Schirmer H, Wilsgaard T, et al. Moderate wine consumption is associated with better cognitive test results: a 7 year follow up of 5033 subjects in the Tromsø Study. Acta Neurol Scand Suppl. 2010;190:23-29.

105. Yamazaki Y, Miwa T, Sakurai H, et al. Clinical backgrounds and morbidity of cognitive impairment in elderly diabetic patients. Endocr J. 2011;58:109-115.

106. Heyman A, Wilkinson WE, Stafford JA, et al. Alzheimer's disease: a study of epidemiological aspects. Ann Neurol. 1984;15:335-341.

107. Hofman A, van Duijn CM. Alzheimer's disease, Parkinson's disease and smoking. Neurobiol Aging. 1990;11:295.

108. Cervilla JA, Prince M, Mann A. Smoking, drinking, and incident cognitive impairment: a cohort community based study included in the Gospel Oak project. J Neurol Neurosurg Psychiatry. 2000;68: 622-626.

109. French LR, Schuman LM, Mortimer JA, et al. A case-control study of dementia of the Alzheimer type. Am J Epidemiol. 1985;121: 414-421.

110. Iliffe S, Haines A, Booroff A, et al. Alcohol consumption by elderly people: a general practice survey. Age Ageing. 1991;20:120-123.

111. Commenges D, Scotet V, Renaud S, et al. Intake of flavonoids and risk of dementia. Eur J Epidemiol. 2000;16:357-363.

112. Amaducci LA, Fratiglioni L, Rocca WA, et al. Risk factors for clinically diagnosed Alzheimer's disease: a case-control study of an Italian population. Neurology. 1986;36:922-931.

113. Hebert LE, Scherr PA, Beckett LA, et al. Relation of smoking and alcohol consumption to incident Alzheimer's disease. Am J Epidemiol. 1992;135:347-355.

114. Galanis DJ, Joseph C, Masaki KH, et al. A longitudinal study of drinking and cognitive performance in elderly Japanese American men: the Honolulu-Asia Aging Study. Am J Public Health. 2000;90: 1254-1259.

115. Guralnik JM, Kaplan GA. Predictors of healthy aging: prospective evidence from the Alameda County study. Am J Public Health. 1989; 79:703-708.

116. Ensrud KE, Nevitt MC, Yunis C, et al. Correlates of impaired function in older women. J Am Geriatr Soc. 1994;42:481-489.

117. Hébert R, Lindsay J, Verreault R, et al. Vascular dementia: incidence and risk factors in the Canadian study of health and aging. Stroke. 2000;31:1487-1493.

118. Yoshitake T, Kiyohara Y, Kato I, et al. Incidence and risk factors of vascular dementia and Alzheimer's disease in a defined elderly Japanese population: the Hisayama Study. Neurology. 1995;45: 1161-1168.

119. Tyas SL, Koval JJ, Pederson LL. Does an interaction between smoking and drinking influence the risk of Alzheimer's disease? results from three Canadian data sets. Stat Med. 2000;19:1685-1696.

120. Hendrie HC, Gao S, Hall KS, et al. The relationship between alcohol consumption, cognitive performance, and daily functioning in an urban sample of older black Americans. J Am Geriatr Soc. 1996;44: 1158-1165.
121. DeCarli C, Miller BL, Swan GE, et al. Cerebrovascular and brain morphologic correlates of mild cognitive impairment in the National Heart, Lung, and Blood Institute Twin Study. Arch Neurol. 2001;58:643-647.

122. Launer LJ, Feskens EJ, Kalmijn S, et al. Smoking, drinking, and thinking: the Zutphen Elderly Study. Am J Epidemiol. 1996;143:219-227.

123. Zuccala G, Onder G, Pedone C, et al. Dose-related impact of alcohol consumption on cognitive function in advanced age: results of a multicenter survey. Alcohol Clin Exp Res. 2001;25:1743-1748.

124. Dufouil C, Ducimetière P, Alperovitch A. Sex differences in the association between alcohol consumption and cognitive performance: EVA Study Group; Epidemiology of Vascular Aging. Am J Epidemiol. 1997;146:405-412.

125. Huang W, Qiu C, Winblad B, et al. Alcohol consumption and incidence of dementia in a community sample aged 75 years and older. J Clin Epidemiol. 2002;55:959-964.

126. Orgogozo JM, Dartigues JF, Lafont S, et al. Wine consumption and dementia in the elderly: a prospective community study in the Bordeaux area. Rev Neurol (Paris). 1997;153:185-192.

127. Lindsay J, Laurin D, Verreault R, et al. Risk factors for Alzheimer's disease: a prospective analysis from the Canadian Study of Health and Aging. Am J Epidemiol. 2002;156:445-453.

128. Tsolaki M, Fountoulakis K, Chantzi E, et al. Risk factors for clinically diagnosed Alzheimer's disease: a case-control study of a Greek population. Int Psychogeriatr. 1997;9:327-341.

129. Ruitenberg A, van Swieten JC, Witteman JC, et al. Alcohol consumption and risk of dementia: the Rotterdam Study. Lancet. 2002;359: 281-286.

130. Edelstein SL, Kritz-Silverstein D, Barrett-Connor E. Prospective association of smoking and alcohol use with cognitive function in an elderly cohort. J Womens Health. 1998;7:1271-1281.

131. Tanaka N, Asada T, Kinoshita T, et al. Alcohol consumption and risk of dementia. Lancet. 2002;360:491.

132. Carmelli D, Swan GE, Reed T, et al. The effect of apolipoprotein E epsilon4 in the relationships of smoking and drinking to cognitive function. Neuroepidemiology. 1999;18:125-133.

133. Truelsen T, Thudium D, Gronbaek M. Amount and type of alcohol and risk of dementia: the Copenhagen City Heart Study. Neurology. 2002;59:1313-1319.

134. Harwood DG, Barker WW, Loewenstein DA, et al. A cross-ethnic analysis of risk factors for AD in white Hispanics and white nonHispanics. Neurology. 1999;52:551-556.

135. Bachman DL, Green RC, Benke KS, et al. Comparison of Alzheimer's disease risk factors in white and African American families. Neurology. 2003;60:1372-1374.

136. Leibovici D, Ritchie K, Ledésert B, et al. The effects of wine and tobacco consumption on cognitive performance in the elderly: a longitudinal study of relative risk. Int J Epidemiol. 1999;28: 77-81.

137. Mukamal KJ, Kuller LH, Fitzpatrick AL, et al. Prospective study of alcohol consumption and risk of dementia in older adults. JAMA. 2003;289:1405-1413.

138. Zhou H, Deng J, Li J, et al. Study of the relationship between cigarette smoking, alcohol drinking and cognitive impairment among elderly people in China. Age Ageing. 2003;32:205-210.

139. Anttila T, Helkala EL, Viitanen M, et al. Alcohol drinking in middle age and subsequent risk of mild cognitive impairment and dementia in old age: a prospective population based study. BMJ. 2004; 329:539

140. Britton A, Singh-Manoux A, Marmot M. Alcohol consumption and cognitive function in the Whitehall II Study. Am J Epidemiol. 2004; 160:240-247.

141. Larrieu S, Letenneur L, Helmer C, et al. Nutritional factors and risk of incident dementia in the PAQUID longitudinal cohort. J Nutr Health Aging. 2004;8:150-154.

142. Luchsinger JA, Tang MX, Siddiqui M, et al. Alcohol intake and risk of dementia. J Am Geriatr Soc. 2004;52:540-546. 
143. Espeland MA, Gu L, Masaki KH, et al. Association between reported alcohol intake and cognition: results from the Women's Health Initiative Memory Study. Am J Epidemiol. 2005;161:228-238.

144. Ganguli M, Bilt J Vander, Saxton JA, et al. Alcohol consumption and cognitive function in late life: a longitudinal community study. Neurology. 2005;65:1210-1217.

145. Järvenpää T, Rinne JO, Koskenvuo M, et al. Binge drinking in midlife and dementia risk. Epidemiology. 2005;16:766-771.

146. Rozzini R, Trabucchi M. Re: “Association between reported alcohol intake and cognition: results from the Women's Health Initiative Memory Study". Am J Epidemiol. 2005;162:294-295; author reply 295-296.

147. Stampfer MJ, Kang JH, Chen J, et al. Effects of moderate alcohol consumption on cognitive function in women. N Engl J Med. 2005;352: 245-253.

148. Dai Q, Pruett SB. Different effects of acute and chronic ethanol on LPS-induced cytokine production and TLR4 receptor behavior in mouse peritoneal macrophages. J Immunotoxicol. 2006;3:217-225.

149. Deng J, Zhou DH, Li J, et al. A 2-year follow-up study of alcohol consumption and risk of dementia. Clin Neurol Neurosurg. 2006;108: 378-383.

150. Gureje O, Ogunniyi A, Kola L, et al. Incidence of and risk factors for dementia in the Ibadan study of aging. J Am Geriatr Soc. 2011;59: 869-874.

151. Ogunniyi A, Hall KS, Gureje O, et al. Risk factors for incident Alzheimer's disease in African Americans and Yoruba. Metab Brain Dis. 2006;21:235-240.

152. Simons LA, Simons J, McCallum J, et al. Lifestyle factors and risk of dementia: dubbo study of the elderly. Med J Aust. 2006;184:68-70.

153. Wright CB, Elkind MS, Rundek T, et al. Alcohol intake, carotid plaque, and cognition: the Northern Manhattan Study. Stroke. 2006; 37:1160-1164.

154. Yip AG, Brayne C, Matthews FE. Risk factors for incident dementia in England and Wales: the Medical Research Council Cognitive Function and Ageing Study; a population-based nested case-control study. Age Ageing. 2006;35:154-160.

155. McGuire LC, Ajani UA, Ford ES. Cognitive functioning in late life: the impact of moderate alcohol consumption. Ann Epidemiol. 2007; 17:93-99.

156. Solfrizzi V, D'Introno A, Colacicco AM, et al. Alcohol consumption, mild cognitive impairment, and progression to dementia. Neurology. 2007;68:1790-1799.

157. Vincze G, Almos P, Boda K, et al. Risk factors of cognitive decline in residential care in Hungary. Int J Geriatr Psychiatry. 2007;22: 1208-1216.

158. Wadley VG, McClure LA, Howard VJ, et al. Cognitive status, stroke symptom reports, and modifiable risk factors among individuals with no diagnosis of stroke or transient ischemic attack in the REasons for Geographic and Racial Differences in Stroke (REGARDS) Study. Stroke. 2007;38:1143-1147.

159. Kivipelto M, Rovio S, Ngandu T, et al. Apolipoprotein E epsilon4 magnifies lifestyle risks for dementia: a population-based study. J Cell Mol Med. 2008;12:2762-2771.

160. Mehlig K, Skoog I, Guo X, et al. Alcoholic beverages and incidence of dementia: 34-year follow-up of the prospective population study of women in Goteborg. Am J Epidemiol. 2008;167: 684-691.

161. Umegaki H, Iimuro S, Kaneko T, et al. Factors associated with lower Mini Mental State Examination scores in elderly Japanese diabetes mellitus patients. Neurobiol Aging. 2008;29:1022-1026.

162. Barnes DE, Covinsky KE, Whitmer RA, et al. Predicting risk of dementia in older adults: the late-life dementia risk index. Neurology. 2009; 73:173-179.

163. Cherbuin N, Reglade-Meslin C, Kumar R, et al. Risk factors of transition from normal cognition to mild cognitive disorder: the PATH through Life Study. Dement Geriatr Cogn Disord. 2009;28: $47-55$.
164. Peters R, Beckett N, Geneva M, et al. Sociodemographic and lifestyle risk factors for incident dementia and cognitive decline in the HYVET. Age Ageing. 2009;38:521-527.

165. Sabia S, Nabi H, Kivimaki M, et al. Health behaviors from early to late midlife as predictors of cognitive function: the Whitehall II study. Am J Epidemiol. 2009;170:428-437.

166. Yaffe K, Fiocco AJ, Lindquist K, et al. Predictors of maintaining cognitive function in older adults: the Health ABC study. Neurology. 2009; 72:2029-2035.

167. Chan KK, Chiu KC, Chu LW. Association between alcohol consumption and cognitive impairment in Southern Chinese older adults. Int J Geriatr Psychiatry. 2010;25:1272-1279.

168. Garcia AM, Ramon-Bou N, Porta M. Isolated and joint effects of tobacco and alcohol consumption on risk of Alzheimer's disease. J Alzheimers Dis. 2010;20:577-586.

169. Lobo E, Dufouil C, Marcos G, et al. Is there an association between low-to-moderate alcohol consumption and risk of cognitive decline? Am J Epidemiol. 2010;172:708-716.

170. Lopes MA, Furtado EF, Ferrioli E, et al. Prevalence of alcohol-related problems in an elderly population and their association with cognitive impairment and dementia. Alcohol Clin Exp Res. 2010;34:726-733.

171. Luck T, Luppa M, Briel S, et al. Mild cognitive impairment: incidence and risk factors: results of the Leipzig longitudinal study of the aged. J Am Geriatr Soc. 2010;58:1903-1910.

172. Smith K, Flicker L, Dwyer A, et al. Factors associated with dementia in Aboriginal Australians. Aust N Z J Psychiatry. 2010;44:888-893.

173. Virtaa JJ, Järvenpää T, Heikkilä K, et al. Midlife alcohol consumption and later risk of cognitive impairment: a twin follow-up study. J Alzheimers Dis. 2010;22:939-948.

174. Yen CH, Yeh CJ, Wang CC, et al. Determinants of cognitive impairment over time among the elderly in Taiwan: results of the national longitudinal study. Arch Gerontol Geriatr. 2010; 50(Suppl 1):S53-S57.

175. Au Yeung SL, Leung GM, Chan WM, et al. Moderate alcohol use and cognitive function in an elderly Chinese cohort. J Am Geriatr Soc. 2011;59:172-174.

176. Kim KW, Park JH, Kim MH, et al. A nationwide survey on the prevalence of dementia and mild cognitive impairment in South Korea. J Alzheimers Dis. 2011;23:281-291.

177. Rusanen M, Kivipelto M, Quesenberry CP, et al. Heavy smoking in midlife and long-term risk of Alzheimer disease and vascular dementia. Arch Intern Med. 2011;171:333-339.

178. Weyerer S, Schäufele M, Wiese B, et al. Current alcohol consumption and its relationship to incident dementia: results from a 3-year follow-up study among primary care attenders aged 75 years and older. Age Ageing. 2011;40:456-463.

179. Goldman E, Najman JM. Lifetime abstainers, current abstainers and imbibers: a methodological note. Br J Addict. 1984;79:309-314.

180. O'Mahony JF, Doherty B. Intellectual impairment among recently abstinent alcohol abusers. Br J Clin Psychol. 1996;35 (Pt 1): 77-83.

181. Fillmore KM, Golding JM, Graves KL, et al. Alcohol consumption and mortality, I: Characteristics of drinking groups. Addiction. 1998; 93:183-203.

182. Leino EV, Romelsjö A, Shoemaker C, et al. Alcohol consumption and mortality, II: Studies of male populations. Addiction. 1998; 93:205-218.

183. Fillmore KM, Golding JM, Graves KL, et al. Alcohol consumption and mortality, III: Studies of female populations. Addiction. 1998; 93:219-229.

184. McCallum J, Simons LA, Simons J, et al. Delaying dementia and nursing home placement: the Dubbo study of elderly Australians over a 14-year follow-up. Ann N Y Acad Sci. 2007;1114:121-129.

185. Harwood DG, Kalechstein A, Barker WW, et al. The effect of alcohol and tobacco consumption, and apolipoprotein E genotype, on the age of onset in Alzheimer's disease. Int J Geriatr Psychiatry. 2010;25: $511-518$ 
186. Bobak M, Richards M, Malyutina S, et al. Association between year of birth and cognitive functions in Russia and the Czech Republic: cross-sectional results of the HAPIEE study. Neuroepidemiology. 2009;33:231-239.

187. Folstein MF, Folstein SE, McHugh PR. "Mini-mental state": a practical method for grading the cognitive state of patients for the clinician. J Psychiatr Res. 1975;12:189-198.

188. Folstein M, Folstein S. Invited reply to "The death knoll for the MMSE: has it outlived its purpose?". J Geriatr Psychiatry Neurol. 2010;23:158-159.

189. Nieuwenhuis-Mark RE. The death knoll for the MMSE: has it outlived its purpose? J Geriatr Psychiatry Neurol. 2010;23:151-157.

190. Mitchell AJ. A meta-analysis of the accuracy of the mini-mental state examination in the detection of dementia and mild cognitive impairment. J Psychiatr Res. 2009;43:411-431.

191. Scarmeas N, Stern Y, Tang MX, et al. Mediterranean diet and risk for Alzheimer's disease. Ann Neurol. 2006;59:912-921.

192. Gu Y, Nieves JW, Stern Y, et al. Food combination and Alzheimer disease risk: a protective diet. Arch Neurol. 2010;67:699-706.

193. Roe CM, Xiong C, Miller JP, et al. Education and Alzheimer disease without dementia: support for the cognitive reserve hypothesis. Neurology. 2007;68:223-228.

194. Scarmeas N, Stern Y. Cognitive reserve: implications for diagnosis and prevention of Alzheimer's disease. Curr Neurol Neurosci Rep. 2004;4:374-380.

195. Mukamal KJ, Chiuve SE, Rimm EB. Alcohol consumption and risk for coronary heart disease in men with healthy lifestyles. Arch Intern Med. 2006;166:2145-2150.
196. Knoops KT, de Groot LC, Kromhout D, et al. Mediterranean diet, lifestyle factors, and 10-year mortality in elderly European men and women: the HALE project. JAMA. 2004;292:1433-1439.

197. Imhof A, Woodward M, Doering A, et al. Overall alcohol intake, beer, wine, and systemic markers of inflammation in western Europe: results from three MONICA samples (Augsburg, Glasgow, Lille). Eur Heart J. 2004;25:2092-2100.

198. Britton A, Marmot MG, Shipley M. Who benefits most from the cardioprotective properties of alcohol consumption: health freaks or couch potatoes? J Epidemiol Community Health. 2008;62:905-908.

199. French MT, Zavala SK. The health benefits of moderate drinking revisited: alcohol use and self-reported health status. Am J Health Promot. 2007;21:484-491.

200. Karlamangla AS, Sarkisian CA, Kado DM, et al. Light to moderate alcohol consumption and disability: variable benefits by health status. Am J Epidemiol. 2009;169:96-104.

201. Tien HC, Tremblay LN, Rizoli SB, et al. Association between alcohol and mortality in patients with severe traumatic head injury. Arch Surg. 2006;141:1185-1191; discussion 1192.

202. Daviglus ML, Bell CC, Berrettini W, et al. National Institutes of Health State-of-the-Science Conference statement: preventing Alzheimer disease and cognitive decline. Ann Intern Med. 2010;153:176-181.

203. Gunzerath L, Faden V, Zakhari S, et al. National Institute on Alcohol Abuse and Alcoholism report on moderate drinking. Alcohol Clin Exp Res. 2004;28:829-847.
Neuropsychiatric Disease and Treatment

\section{Publish your work in this journal}

Neuropsychiatric Disease and Treatment is an international, peerreviewed journal of clinical therapeutics and pharmacology focusing on concise rapid reporting of clinical or pre-clinical studies on a range of neuropsychiatric and neurological disorders. This journal is indexed on PubMed Central, the 'PsycINFO' database and CAS, and is the official

\section{Dovepress}

journal of The International Neuropsychiatric Association (INA). The manuscript management system is completely online and includes a very quick and fair peer-review system, which is all easy to use. Visit $\mathrm{http}: / /$ www.dovepress.com/testimonials.php to read real quotes from published authors. 